\title{
Development and Characterization of a PHB- HV-based 3D Scaffold for a Tissue Engineering and Cell-therapy Combinatorial Approach for Spinal Cord Injury Regeneration
}

\author{
Silvina Ribeiro-Samy, Nuno A. Silva, Vitor M. Correlo, ${ }^{*}$ Joana S. Fraga, \\ Luísa Pinto, Andreia Teixeira-Castro, Hugo Leite-Almeida, Armando Almeida, \\ Jeffrey M. Gimble, Nuno Sousa, António J. Salgado, ${ }^{*}$ Rui L. Reis
}

Spinal cord injury (SCI) leads to devastating neurological deficits. Several tissue engineering (TE)based approaches have been investigated for repairing this condition. Poly (3-hydroxybutyrateco-3-hydroxyvalerate) (PHB-HV) is found to be particularly attractive for TE applications due to its properties, such as biodegradability, biocompatibility, thermoplasticity and piezoelectricity. Hence, this report addresses the development and characterization of PHB-HV-based 3D scaffolds, produced by freeze-drying, aimed to SCI treatment. The obtained scaffolds reveal an anisotropic morphology with a fully interconnected network of pores. In vitro studies demonstrate a lack of cytotoxic effect of PHB-HV scaffolds. Direct contact assays also reveal their ability to support the culture of CNS-derived cells and mesenchymal-like stem cells from different sources. Finally, histocompatibility studies show that PHB-HV scaffolds are well tolerated by the host tissue, and do not negatively impact the left hindlimb locomotor function recovery. Therefore results herein presented suggest that PHB-HV scaffolds may be suitable for SCI treatment.

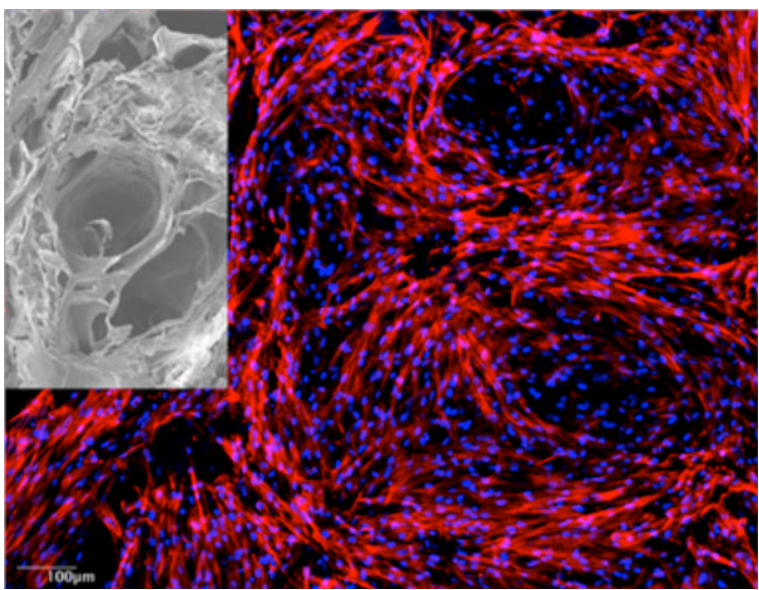

Dr. V. M. Correlo, S. Ribeiro-Samy, Dr. N. A. Silva, Prof. R. L. Reis 3B's Research Group - Biomaterials, Biodegradables and Biomimetics, Department of Polymer Engineering, University of Minho, Headquarters of the European Institute of Excellence on Tissue Engineering and Regenerative Medicine, AvePark, 4806-909, Taipas, Guimarães, Portugal

E-mail: vitorcorrelo@dep.umninho.pt

Dr. A. J. Salgado, S. Ribeiro-Samy, Dr. N. A. Silva, J. S. Fraga,

Dr. L. Pinto, Dr. A. Teixeira-Castro, Dr. H. Leite-Almeida,

Prof. A. Almeida, Prof. N. Sousa

S. Ribeiro-Samy, Dr. N. A. Silva, Dr. V. M. Correlo, J. S. Fraga, Dr. L. Pinto, Dr. A. Teixeira-Castro, Dr. H. Leite-Almeida, Prof. A. Almeida, Prof. N. Sousa, Dr. A. J. Salgado,

Prof. R. L. Reis

ICVS/3B's-Associate Laboratory, PT Government Associate Laboratory, Braga/Guimarães, Portugal

Prof. J. M. Gimble

Pennington Biomedical Research Center, Louisiana State University System, Baton Rouge, Louisiana, USA

Life and Health Sciences Research Institute (ICVS), School of

Health Sciences, University of Minho-Campus de Gualtar,

4710-057 Braga, Portugal

E-mail: asalgado@ecsaude.uminho.pt 


\section{Introduction}

Spinal cord injury (SCI) leads to devastating neurological deficits and disabilities which result in physical and lifestyle constraints that totally reconfigures daily life. ${ }^{[1,2]}$ Annually, 12.1-57.8 per million people worldwide are afflicted with SCI. ${ }^{[3]}$ This condition imposes enormous psychosocial and financial costs to patients, their relatives, and the community, representing a significant health problem associated with the lifelong disability. ${ }^{[1,4]}$ Current approaches used in the clinical practice to treat this condition are generally limited to the reduction of pain and inflammation, through the administration of antiinflammatory drugs, as well as the prevention of secondary injuries. ${ }^{[5]}$ Until 2009, only six drugs had been tested in phase III clinical trials: methylprednisolone, ${ }^{[6]}$ naloxone, ${ }^{[7]}$ tirilazad mesylate, ${ }^{[8,9]}$ monosialoganglioside $\mathrm{GM1}{ }^{[10]}$ 4-aminopyridine, ${ }^{[11]}$ and tizanidine. ${ }^{[12]}$ So far, methylprednisolone has been the only one to have shown some beneficial effects in acute SCI. ${ }^{[13,14]}$ Other approaches such as cellular, biomolecular, and biomaterial-based therapies have been investigated for managing this condition. However, to date no single repair strategy has successfully induced full functional recovery following SCI. ${ }^{[1,5]}$ Considering the complexity of SCI pathophysiology many experts agree that the greatest hope for SCI repair will involve a combinatorial approach that integrates biomaterials, cell transplantation, and molecule delivery such as that presented by tissue engineering (TE). ${ }^{[5,15-18]}$ In this field, three-dimensional porous scaffolds can be used as temporary extracellular matrix (ECM) that support cellular adhesion and proliferation by mimicking the in vivo environment, and thus foster tissue regeneration. ${ }^{\text {[19-22] }}$ Some of the biomaterials used for the production of scaffolds aimed for SCI applications include collagen, agarose, alginate, hyaluronic acid, chitosan, fibrin, and several synthetic polymers such as poly(lactic acid) (PLA), poly(glycolic acid) (PGA), poly(D,L-lactic acid-co-glycolic acid (PLGA), and polyethylene glycol (PEG) among others. ${ }^{[23]}$ Previous studies have shown that limited gliosis, ${ }^{[24,25]}$ axonal regrowth, ${ }^{[26-28]}$ neuronal regeneration, ${ }^{[29-31]}$ and some functional recovery after spinal cord transection in animal models ${ }^{[32-34]}$ can be achieved using several biomaterial-based scaffolds per se or in combination with both cellular and biomolecular therapies. However, many of the studied scaffolds also present drawbacks, such as, cytotoxicity associated with the grafted biomaterial, partial or total collapse of the grafted structure, and inadequate degradation rate of the biomaterial in vivo (reviewed by Madigan et al. ${ }^{[23]}$ and Nomura et al. ${ }^{[35]}$ ).

Therefore, there is an urgent need for the development of scaffolds based on other biomaterials, than those previously discussed. Thus, in the present study we aimed at developing a 3D structure for SCI repair based on poly(3- hydroxybutyrate-co-3-hydroxyvalerate) (PHB-HV). The latter is a copolymer of the bacterial polyester poly(3hydroxybutyrate) (PHB), that is accumulated by bacteria as a carbon and energy storage source. ${ }^{[36]}$ This biomaterial is found to be particularly attractive for TE applications due to its properties, such as, optical activity, biodegradability, biocompatibility, non-toxicity, thermoplasticity, piezoelectricity, and more adjustable properties depending upon copolymer composition when compared to PHB. ${ }^{[37,38]}$ Moreover, in vivo, PHB-HV undergoes hydrolytic degradation producing $(R)$-3-hydroxybutyric acid ${ }^{[39,40]}$ and 3hydroxyvaleric acid-ketone bodies that already exist in the blood under normal physiological conditions-not known to lead to long term tissue reactions at the implantation site. ${ }^{[39-41]}$ Furthermore, Chen and Tong ${ }^{[42]}$ have recently reported the ability of PHB-HV-based microspheres to support a variety of neuronal cell types and promote greater axon-dendrite segregation.

In this report, we address the morphological, mechanical, and biological characterization of PHB-HV-based 3D scaffolds aimed for SCI regeneration. For this purpose, PHB-HV 3D scaffolds produced by freeze-drying were characterized and its suitability for the treatment of SCI was assessed through cytotoxicity evaluation and direct contact assays performed with different cell populations relevant for SCI regeneration. Moreover, in vivo histocompatibility assays in a subcutaneous model and locomotor function recovery, in a hemisection rat model of SCI, were also performed.

\section{Experimental Section}

\subsection{PHB-HV 3D Scaffolds Preparation and Characterization}

PHB-HV 3D scaffolds were produced through an emulsion freezing/freeze-drying technique described by Sultana and Wang. ${ }^{[39]} 7.5 \% \quad(m / v)$ PHB-HV (12\% HV content) polymer powder with a molecular weight of approximately $425.692 \mathrm{kDa}$ (PHB Industrial, Brazil), chloroform $(\varphi=0.5)$ (VWR InternationalLaboratorial Material Ltd., Portugal) and acetic acid $(\varphi=0.5)$ (Panreac, Spain) were used for the emulsion preparation.

Briefly, PHB-HV powder was dissolved in chloroform at $65^{\circ} \mathrm{C}$, under constant magnetic stirring. After obtaining a homogeneous polymer solution, acetic acid (1:1) was added and the emulsion was stored overnight at $-80^{\circ} \mathrm{C}$. Subsequently, the frozen emulsion was lyophilized (Telstar, Spain) at $-80^{\circ} \mathrm{C}$ for $94 \mathrm{~h}$. By adding acetic acid (water phase), two immiscible phases are created, where the continuous phase contains the polymer-rich solvent and the dispersed phase is water. With this approach it is possible to have a better control over porosity and pore size than just freeze-drying the polymer solution. The scaffolds produced were stored in a hotte at room temperature to promote the evaporation of any residual solvent until being cut in smaller cylindrical pieces of $4 \mathrm{~mm}$ in diameter and $5 \mathrm{~mm}$ in height and sterilized through the action of ethylene oxide (Pronefro, Portugal). 


\subsubsection{Scanning Electron Microscopy}

Scanning electron microscopy (SEM) was used to study the morphology/interconnectivity of the pores within the 3D structure of the PHB-HV scaffolds. For this purpose, all samples were coated with $\mathrm{Au} / \mathrm{Pd}$ through ion-sputtering before observation in a Stereoscan 360 scanning electron microscope (Leica Cambridge Co., United Kingdom).

\subsubsection{Micro-Computed Tomography ( $\mu$-CT) Assessment}

The general architecture, porosity and pore size of the scaffolds was assessed by $\mu$-CT (SkyScan 1072, Belgium), using a high resolution mode of $6.9 \mu \mathrm{m} x / y / z$ and an exposure time of $1792 \mathrm{~ms}$. The energy parameters defined in the scanner were $50 \mathrm{kV}$ and $185 \mu \mathrm{A}$. Afterward, the obtained data was processed using NRecon, CT-An, and CT-Vol image software's (Sky Scan, Belgium) for $\mu$-CT reconstruction, analysis, and visualization of the 3D scaffold representation. Then, to determine the percentage of porosity and average pore size, a volume of interest (VOI) consisting of 300 layers with a circular region of interest (ROI) with $\cong 4 \mathrm{~mm}$ diameter was selected for each scaffold. A threshold (to distinguish polymeric material from pore voids) of 60-255 was chosen and maintained constant for all the scanned specimens.

\subsubsection{Compressive Mechanical Properties Evaluation}

Mechanical performance of the developed scaffolds was assessed through compression testing using an universal mechanical testing equipment (Instron 5540, United Kingdom) at a cross-head speed of $2 \mathrm{mmmin}^{-1}$, under both dry and wet (after a $3 \mathrm{~h}$ incubation period in phosphate buffer saline $0.1 \mathrm{M}, \mathrm{pH} 7.2$ at $37^{\circ} \mathrm{C}$ ) conditions. Seven replicates were conducted. For both cases, the compressive modulus was determined on the most linear part of the stress-strain curve.

\subsection{In Vitro Cytotoxicity Evaluation}

Short-term cytotoxicity of the developed scaffolds was assessed as previous described by Salgado et al. ${ }^{[43]}$ For this purpose minimum essential medium (MEM) extraction and MTS tests were performed with a $1,7,14,21$, and 28 d of extraction. The MEM extraction test is aimed to evaluate changes in cell morphology and growth inhibition, whereas the MTS test establishes whether cells are metabolically active. ${ }^{[44,45]}$

In all tests performed, latex rubber (Kimberly-Clark, USA) and standard culture medium (formulation described below) were used as negative and positive controls for cell viability, respectively. After each period the extracts were collected and filtered through a $0.20 \mu \mathrm{m}$-pore-size filter. These assays allow the assessment of the possible toxic effect of the leachables released from the biopolymers during the extraction.

\subsubsection{In Vitro Cell Culture}

For the in vitro cytotoxicity evaluation a mix primary culture of neurons and astrocytes from the hippocampus of P4 Wistar rats (Charles River Laboratories, Barcelona, Spain) were used.
Hippocampus derived primary cell cultures were allowed to grow in Neurobasal-A (Invitrogen, USA) supplemented with 2\% B27 (Invitrogen, USA), $0.25 \% \mathrm{bFGF}$ (Gibco, USA), 0.5\% Glutamax (Invitrogen, USA), and $1 \%$ Kanamycin (Invitrogen, USA), at $37^{\circ} \mathrm{C}$ in a humidified atmosphere with $5 \% \mathrm{v} / \mathrm{v} \mathrm{CO}_{2}$, for $5 \mathrm{~d}$. Cultures were then incubated with $1 \mathrm{~mL}$ well ${ }^{-1}$ of extraction fluid for $72 \mathrm{~h}$ at $37^{\circ} \mathrm{C}$, in a $5 \% \mathrm{v} / \mathrm{v} \mathrm{CO}_{2}$ humidified atmosphere.

\subsubsection{MEM Extraction Test}

Seventy-two hours after culture in extraction fluid, an immunocytochemistry procedure was conducted. The immunocytochemichal staining with mouse anti-rat microtubule associated protein 2 (MAP2) (Sigma, MO, USA) and rabbit anti-rat glial fibrillary acid protein (GFAP) (Dako, Denmark) antibodies was performed according to the protocol described by Salgado et al. ${ }^{[46]}$ Upon staining, cultures were observed under a fluorescence microscope (Olympus BX-61, Germany) and images were captured by a digital camera (DP70, Olympus Corporation, Germany).

\subsubsection{MTS Test}

Cells metabolic viability after exposure to the extraction fluids was assessed using the substrate [3-(4,5-dimethylthiazol-2-yl)-5-(3carboxymethoxyphenyl)-2(4-sulfophenyl)-2H tetrazolium] (MTS; CellTiter $96 \mathrm{AO}_{\text {ueous }}$ One Solution Cell Proliferation Assay; Promega, USA) which is reduced into a brown formazan product by dehydrogenases enzymes active in all metabolically viable cells. ${ }^{[45]}$ The extraction procedure was conducted as follows. After $72 \mathrm{~h}$ of incubation, the extraction fluids were replaced for $500 \mu \mathrm{L} \mathrm{well}^{-1}$ of neurobasal-a medium containing MTS, in a 5:1 ratio. Cultures were then incubated for $3 \mathrm{~h}$ in a humidified atmosphere at $37^{\circ} \mathrm{C}$ and $5 \% \mathrm{v} / \mathrm{v} \mathrm{CO}_{2}$. Following this period, triplicates of $100 \mu \mathrm{L}$ of solution from each sample were transferred to 96-well plates and the optical density (O.D.) was measured at $490 \mathrm{~nm}$ using a multi-well plate reader (Bio-Rad, USA).

\subsection{Direct Contact Assays}

Before seeding, PHB-HV scaffolds were coated with poly-D-lysine (PDL; Sigma, MO, USA) and incubated in culture medium at $37^{\circ} \mathrm{C}$ and $5 \% \mathrm{v} / \mathrm{v} \mathrm{CO}_{2}$ for $3 \mathrm{~h}$ to allow culture medium uptake. Several cell populations were used to conduct direct contact assays with PHBHV scaffolds.

Primary Cultures of Hippocampus Derived Cells: As previously referred hippocampus derived primary cell cultures were prepared from $\mathrm{P} 4$ Wistar rats. Briefly, after brain dissection, hippocampi were submitted to a $2.5 \%$ trypsin based enzymatic digestion and subsequent mechanical dissociation. ${ }^{[46]}$ Upon isolation cells were seeded into the scaffolds at a density of $2 \times 10^{5}$ cells per scaffold $(n=5)$. Two-hours after static seeding the cells/scaffold constructs were incubated in culture medium (formulation described in Section 2.2.1.) for $48 \mathrm{~h}, 7$ and $14 \mathrm{~d}$, at $37^{\circ} \mathrm{C}$ and $5 \% \mathrm{v} / \mathrm{v} \mathrm{CO}$. The culture medium was routinely replaced every 2-3 d until the end of the experiment.

Primary Cultures of Cortical Glial Cells: Cortical glial cells were isolated from newborn Wistar rats (P4). After dissection, cortices were enzymatically digested (30 $\mathrm{U} \mathrm{mL}^{-1}$ DNAse, 0.25\% Trypsin, both from Sigma, MO, USA) followed by mechanical

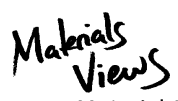

www.MaterialsViews.com
Macromol. Biosci. 2013, DOI: 10.1002/mabi.201300178

(C) 2013 WILEY-VCH Verlag GmbH \& Co. KGaA, Weinheim

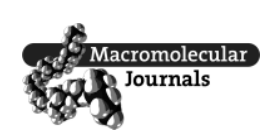

Early View Publication; these are NOT the final page numbers, use DOI for citation !! 
dissociation. ${ }^{[46]}$ Upon isolation, cortical glial cells were seeded into the scaffolds at a density of $2 \times 10^{5}$ cells per scaffold $(n=4)$. Then the cells/scaffold constructs were incubated in culture medium (DMEM, Sigma, MO, USA; 10\% FBS, Invitrogen, USA; 1\% antibiotic-antimycotic mixture, Sigma, MO, USA) for $48 \mathrm{~h}, 7$ and $14 \mathrm{~d}$, at $37^{\circ} \mathrm{C}$ and $5 \% \mathrm{v} / \mathrm{v} \mathrm{CO}_{2}$. The culture medium was routinely replaced every 2-3 $d$ until the end of the experiment.

Human Umbilical Cord Perivascular Cells (HUCPVCS): HUCPVCs were isolated according to the procedures described by Sarugaser et al. ${ }^{[4]}$ and cultured as monolayers in Alpha MEM (Invitrogen, USA) medium supplemented with $10 \%$ FBS and 1\% antibiotic-antimycotic mixture. Upon confluency, cells at passage 4 were detached and seeded into the scaffolds as previously described for hippocampus and glia cultures, at a density of $5 \times 10^{4}$ cells per scaffold $(n=3)$. Subsequently, cells/scaffold constructs were incubated in culture medium (formulation described above) for $48 \mathrm{~h}$ and $7 \mathrm{~d}$, at $37^{\circ} \mathrm{C}$ and $5 \% \mathrm{v} / \mathrm{v} \mathrm{CO}_{2}$. The culture medium was routinely replaced every 2-3 d until the end of the experiment.

Bone Marrow Derived Mesenchymal Stromal Cells (BM-MSCS): BMMSCs, acquired from Lonza (Switzerland), were cultured as monolayers in Alpha MEM medium supplemented with 10\% FBS and $1 \%$ antibiotic-antimycotic mixture, in sterile T175 tissue culture flasks. Upon confluency, cells at passage 4 were detached and seeded into the scaffolds at a density of $5 \times 10^{4}$ cells per scaffold $(n=3)$ and submitted to the same culture conditions described for HUCPVCs.

Adipose-Derived Adult Stem Cells (ASCs): ASCs isolated according to the protocol described by Gimble and Guilak, ${ }^{[48]}$ were cultured as monolayers in Alpha MEM medium supplemented with $10 \%$ FBS and $1 \%$ antibiotic-antimycotic mixture, in sterile T175 tissue culture flasks. Again, upon confluency, cells at passage 4 were detached and seeded into the scaffolds at a density of $5 \times 10^{4}$ cells scaffold $(n=3)$ and maintained in culture as described for HUCPVCs.

Olfactory Ensheathing Cells (OECs): Olfactory ensheathing cells were isolated from the olfactory bulbs of newborn Wistar rats (P4) and cultured as previously described. ${ }^{[49]}$ Briefly, after dissection, the olfactory bulb tissue was enzymatically digested $(0.125 \%$ Collagenase type I, $50 \mathrm{U} \mathrm{mL}^{-1}$ DNAse, both from Sigma, MO, USA) followed by mechanical dissociation. After isolation, the cell suspension was transferred to uncoated 6-well plates and incubated for $54 \mathrm{~h}$ at $37{ }^{\circ} \mathrm{C}$ and $5 \% \mathrm{v} / \mathrm{v} \mathrm{CO}_{2}$, in order to allow the attachment of both fibroblasts and astrocytes. Subsequently, OECs were cultured in DMEM/F12 medium (Invitrogen, USA) supplemented with $2 \%$ FBS, $1 \%$ antibiotic-antimycotic mixture, $0.04 \%$ Bovine Pituitary Extract (BPE, Gibco, USA), 0.008\% Forskolin (Fsk, Sigma, MO, USA) and $0.25 \%$ bFGF. Upon approximately $90 \%$ confluence, cells at passage 1 were then harvested and seeded into the scaffolds as described before, at a density of $2 \times 10^{5}$ cells scaffold $(n=4)$. Afterwards, cells/scaffold constructs were incubated in culture medium (formulation described above) for $48 \mathrm{~h}, 7$ and $14 \mathrm{~d}$, at $37^{\circ} \mathrm{C}$ and $5 \% \mathrm{v} / \mathrm{v} \mathrm{CO}_{2}$. The culture medium was routinely replaced every 3-4 $d$ until the end of the experiment.

\subsubsection{Cell Metabolic Viability Assessment by MTS Assay}

After each culture period, cell metabolic viability was assessed using the MTS test. The cells/scaffold constructs were transferred to new 24-well plates and immersed in a mixture containing serum-free cell culture medium and MTS reagent in a 5:1 ratio. The procedure was then carried out as described in Section 2.2.3.

\subsubsection{Cell Proliferation Assays}

Cell proliferation was assessed using ELISA BrdU colorimetric test (Roche, USA) which allows the assessment of cell proliferation within a $24 \mathrm{~h}$ period and a fluorimetric double-stranded DNA (dsDNA) quantification kit (PicoGreen, Molecular Probes, USA) for the ascertainment of the overall cell proliferation throughout the experimental time points. Both tests were executed according to manufacturer's instructions.

For the ELISA BrdU test, the cells/scaffold constructs were incubated with $10 \mu \mathrm{M}$ BrdU for $24 \mathrm{~h}$ prior to the completion of each time point, after which they were immersed in FixDenat solution (Roche, USA). Subsequently, the constructs were incubated in a solution containing Anti-BrdU-POD reagent (Roche, USA) for $1 \mathrm{~h}$ and a half. After this, the constructs were rinsed three times with PBS $0.1 \mathrm{M} \mathrm{pH} 7.2$ and incubated with TMB reagent (Roche, USA) for $15 \mathrm{~min}$. The reaction product was then quantified by measuring the absorbance at $370 \mathrm{~nm}$ against a reference wavelength of $492 \mathrm{~nm}$ using an ELISA plate reader (Bio-Rad, USA).

To determine the total amount of dsDNA a fluorimetric dsDNA quantification kit was used. Samples were collected at each culture period rinsed three times with PBS $0.1 \mathrm{M} \mathrm{pH} 7.2$ and transferred into microtubes containing $1 \mathrm{~mL}$ of ultrapure water. The cells/scaffold constructs were then stored at $-80^{\circ} \mathrm{C}$ for further analysis. Prior to DNA quantification, samples were thawed and sonicated for 15 min. Standards were prepared with concentrations ranging between 0 and $2 \mu \mathrm{g} \mathrm{mL}^{-1}$. Afterward sample or standard, PicoGreen solution and Tris-HCl-EDTA buffer were added to each well of an opaque 96-well plate (Costar, USA) and incubated in the dark for $10 \mathrm{~min}$. Following this period the fluorescence was measured using an excitation wavelength of $480 \mathrm{~nm}$ and an emission wavelength of $520 \mathrm{~nm}$.

\subsubsection{Cells Distribution within the PHB-HV Scaffolds}

CNS-derived cells distribution within the scaffolds was assessed through immunocytochemistry performed after each culture period according to the protocol described by Salgado et al. ${ }^{[46]}$ For this purpose the following antibodies were used: mouse antirat MAP2 to detect mature neurons; rabbit anti-rat GFAP to detect astrocytes; mouse anti-rat O4 (RD System, USA) for detection of oligodendrocytes; and mouse anti-rat $\mathrm{CD} 11 \mathrm{~b}$ (BD Pharmingen, USA) for detection of microglia.

The distribution of HUCPVCs, BM-MSCs, ASCs, and OECs within the scaffolds was evaluated using a combination of phalloidin (Sigma, MO, USA) and DAPI (Sigma, MO, USA). For this purpose, after each culture period the cells/scaffold constructs were rinsed three times with PBS $0.1 \mathrm{~m} \mathrm{pH} \mathrm{7.2,} \mathrm{and} \mathrm{incubated} \mathrm{with} 4 \%$ paraformaldehyde (PFA; Merck, Germany) for $45 \mathrm{~min}$. Subsequently, the samples were incubated with phalloidin during $45 \mathrm{~min}$ followed by the incubation with DAPI for $10 \mathrm{~min}$. Throughout the several steps of the staining procedure the cells/scaffold constructs were washed with PBS $0.1 \mathrm{~m} \mathrm{pH} \mathrm{7.2.}$

Upon staining, the samples were cut in half ( $2 \mathrm{~mm}$ depth) and both the inner and the outer surface observed under a confocal
Macromol. Biosci. 2013, DOI: 10.1002/mabi.201300178

(C) 2013 WILEY-VCH Verlag GmbH \& Co. KGaA, Weinheim

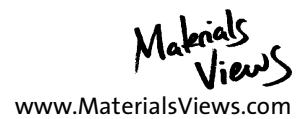

Early View Publication; these are NOT the final page numbers, use DOI for citation !! 
fluorescence microscope (Fluoview FV 1000, Olympus Corporation, Germany).

All the former described experiments were performed twice to guarantee the reproducibility of the obtained results.

\subsection{In Vivo Histocompatibility Evaluation}

\subsubsection{Subcutaneous Implantation}

Wistar rats were purchased from Charles River. Animals were housed in pairs under standard conditions of light, temperature, and humidity. Water and food (standard diet.) ad libitum. The maintenance and manipulation of the animals were in accordance with the Federation of European Laboratory Animal Sciences Associations Directive 2010/63/EU. A mixture of ketamine (Imalgene-75 $\mathrm{mg} \mathrm{kg}^{-1}$; Merial, Portugal) and medetomidine (Dorbene Vet $-0.5 \mathrm{mg} \mathrm{kg}^{-1}$; Esteve Veterinária, Portugal) was used to anesthetize the rats. Once anaesthetized, four incisions per animal were performed (reaching a maximum of $1.5 \mathrm{~cm}$ each) being two in the interscapular region and the other two in the lumbar region. With the help of a forceps one side pocket was created through each of the incisions and PHB-HV scaffolds were implanted subcutaneously in a total of nine animals. Four scaffolds were implanted per animal, being two on the anterior region and other two on the posterior region. The incision sites were sutured and upon recovery from anesthesia the rats were returned to their respective compartments and kept under food and drink ad libitum. The subcutaneous implants were maintained for 1, 4, and 12 weeks (three animals/time point). At the end of each time point, sodium pentobarbital (Eutasil-150 $\mathrm{mg} \cdot \mathrm{kg}^{-1}$; Ceva Saúde Animal, Portugal) was intraperitoneally injected to euthanize the animals. The scaffolds were removed, fixed in 3.7\% formaldehyde (Labsolve-JMGS Lda., Portugal), processed for paraffin type 6 (Richard-Allan Scientific, USA) embedding, and stained with hematoxylin-eosin (H\&E, Leica Auto Stainer XL, United Kingdom).

\subsubsection{Hemisection Rat Model of SCI}

A total of 8 Wistar rats (Charles River) were anesthetized by intraperitoneal injection of a mixture of ketamine (Imalgene:75 $\mathrm{mg} \mathrm{kg}^{-1}$; Merial, Portugal) and medetomidine (Dorbene Vet: $0.5 \mathrm{mg} \mathrm{kg}^{-1}$; Esteve Veterinária, Portugal). Once anaesthetized, fur was shaved from the surgical site and the skin disinfected with chlorohexidine (AGB). Then a dorsal midline incision was made from T6-T11 and the paravertebral muscles retracted. A laminectomy was performed at the junction T8-T9 in which the spinous processes were removed and the spinal cord exposed. Two hemisections were performed on the left side $3 \mathrm{~mm}$ apart of each other and the tissue in between removed. After SCI, PHB-HV scaffolds were implanted in the injury site followed by the implantation of a 3D semi-tubular starch/polycaprolactone (SPCL) scaffolds at the vertebral bone level, juxtaposed to the spinal cord providing spine stabilization, as previously described by Silva et al. ${ }^{[50]}$ Bone cement (Biomet, USA) was used to fix the SPCL scaffolds margins to bone. After scaffolds implantation, paravertebral muscles and skin were separately closed with Vicryl sutures (Johnson and Johnson, USA). Animals were divided into two experimental groups: animals with spine stabilization (control, $n=4$ ), and animals with PHB-HV scaffold implantation and spine stabilization (PHB-HV, $n=4$ ). Handling was performed for $3 \mathrm{~d}$ before the surgery.

Following SCI surgery rats were kept under heat lamps and received vitamins (Duphalyte- $1 \mathrm{~mL} \mathrm{~kg}^{-1} \mathrm{~d}^{-1}$, Farmoquil-Sociedade Farmo-química, Lda., Portugal), analgesic (Butorphanol tartrate $-5 \mathrm{mg} \mathrm{kg}^{-1} \mathrm{~d}^{-1}$, Plurivet-Veterinária e Pecuária, Lda., Portugal), antibiotic (Enrofloxacine- $5 \mathrm{mg} \mathrm{kg}^{-1} \mathrm{~d}^{-1}$, Bayer Portugal, S.A., Portugal) and saline solution ( $\mathrm{NaCl} 0.9 \%-10 \mathrm{~mL} \mathrm{~kg}^{-1}$ $\mathrm{d}^{-1}$, Ultimédica, Portugal), daily for the first $72 \mathrm{~h}$. Bladder evacuation was done manually. Throughout the treatment and recovery period, animals were examined for symptoms of illness or potential reaction to the treatment.

\subsubsection{Assessment of Locomotor Function by BBB Test}

All rats were assessed with the Basso, Beattie, Bresnahan Locomotor Rating Scale $(\mathrm{BBB})^{[51]}$ on weeks $1,2,3$, and 4 after injury. The $\mathrm{BBB}$ is a 21-point scale designed to assess hindlimb locomotor function recovery following SCI. A BBB score of 0 indicates no spontaneous hindlimb movement. A BBB score of 1 through 8 indicates isolated joint movements, but no weight support. A BBB score of 9 through 20 indicates an ability to support weight and use the limb for locomotion but with some degree of abnormality. A BBB score of 21 corresponds to the normal locomotion pattern of a rat.

\subsubsection{Tissue Preparation}

Four weeks after scaffolds implantation the rats were deeply anesthetized through an intraperitoneal injection of sodium pentobarbital (Eutasil: $150 \mathrm{mg} \mathrm{kg}^{-1}$; Ceva Saúde Animal, Portugal). Next, the animals were perfused through the ascending aorta with $4 \%$ PFA in PBS 0.1 M pH 7.2. A $2.5-3 \mathrm{~cm}$ length of spine, centered on the site of hemisection and scaffold placement, was carefully removed and fixed in neutral buffered formalin (Labsolve, JMGS Lda., Portugal). After fixation, the spines were processed for paraffin type 6 (Richard-Allan Scientific, USA) embedding, and stained with H\&E (Leica Auto Stainer XL, United Kingdom). The tissue was sectioned on the coronal plane and tissue infiltration/organization was evaluated on slices of the median cord subdivision.

\subsection{Statistical Analysis}

Statistical analysis was performed using GraphPad Prim 5.00 software for Windows (GraphPad Software, San Diego, USA). Statistical evaluation was performed using the one-way analysis of variance (ANOVA) test followed by the Tukey post hoc test, to assess the statistical differences regarding cell viability and proliferation inside the scaffolds between the different cell culture periods. Evaluation of statistical differences concerning in vitro cytotoxicity assays, cell viability and proliferation inside the scaffolds between the different types of mesenchymal-like stem cells studied, and in vivo locomotor function assessment was scrutinized through a two-way ANOVA test followed by a Bonferroni post hoc test. Statistical significant values were defined for $p<0.05$.

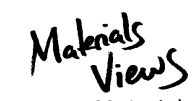

www.MaterialsViews.com
Macromol. Biosci. 2013, DOI: 10.1002/mabi.201300178

(C) 2013 WILEY-VCH Verlag GmbH \& Co. KGaA, Weinheim

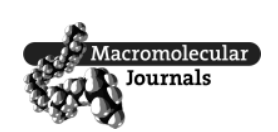

Early View Publication; these are NOT the final page numbers, use DOI for citation !! 


\section{Results}

\subsection{PHB-HV Scaffolds Characterization}

The $7.5 \%(\mathrm{~m} / \mathrm{v})$ PHB-HV scaffolds produced by freezedrying technique revealed a cross macro-structure presenting organized laminar porous (Figure $1 \mathrm{a}-\mathrm{c}$ ), while its longitudinal macro-structure exhibited round pores (Figure 1d-f). The scaffolds were analyzed by microCT for morphometric analysis and 3D reconstruction (Figure 2). These analyses revealed that PHB-HV scaffolds possess an average pore size of $163.5 \pm 0.1 \mu \mathrm{m}$ and a porosity of $88.1 \pm 0.3 \%$.

The compressive mechanical tests revealed that PHB-HV scaffolds exhibit an anisotropic behavior, with a compressive modulus of $1.4 \pm 0.7 \mathrm{MPa}$ on the longitudinal direction (Table 1) and a compressive modulus of $2.9 \pm 0.3 \mathrm{MPa}$ on the cross-section direction (Table 1). Such evidence is in accordance with the anisotropic features of these structures unveiled by the SEM analysis results. Moreover, it was also possible to observe that after $3 \mathrm{~h}$ incubation the compressive modulus of these structures had decreased approximately $50 \%$ on the longitudinal direction and approximately $69 \%$ on the cross-section direction (Table 1 ).

\subsection{In Vitro Cytotoxicity Evaluation of PHB-HV Scaffolds}

The cytotoxicity of PHB-HV scaffolds was assessed using hippocampus derived primary cell cultures to ascertain the effect of PHB-HV degradation products over hippocampal neurons and astrocytes. The MEM extraction test associated with immunocytochemistry staining (Figure $3 \mathrm{a}$ ) revealed that cells density and morphology were very similar between the cells incubated in PHB-HV extracts, collected at different time points, and the cells grown in Neurobasal-A medium (positive control), contrasting the notorious absence of viable neurons observed in cells grown in Neurobasal-A medium containing latex leachables (negative control). The immunocytochemistry staining evidences were further confirmed by the MTS test (Figure 3b), under which cells produced large amounts of a brown formazan product after incubation with both Neurobasal-A medium and the scaffolds' extracts. This is an indicator of metabolic viability as cells incubated with some of the degradation products of the PHB-HV scaffolds were able to incorporate and metabolize MTS.

\subsection{Interaction between CNS-derived Cells and PHB-HV Scaffolds}

Since the aim of this work was to investigate the therapeutic potential of PHB-HV based-scaffolds for SCI regeneration, the interaction between primary cultures of CNS-derived cells (primary cultures of both hippocampal and cortical glial cells) and the developed scaffolds was studied. For this purpose cell morphology, metabolic viability, and proliferation were assessed by immunocytochemistry, MTS test and, ELISA BrdU test and dsDNA quantification, respectively.
A

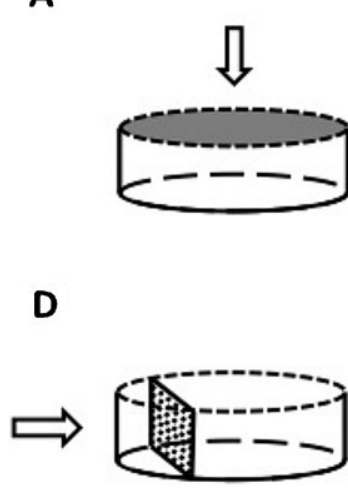

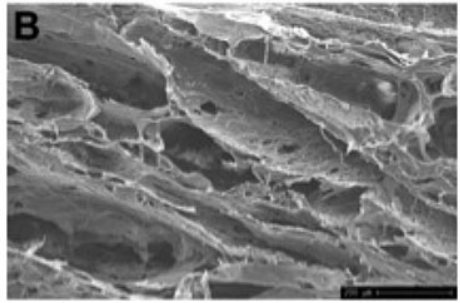
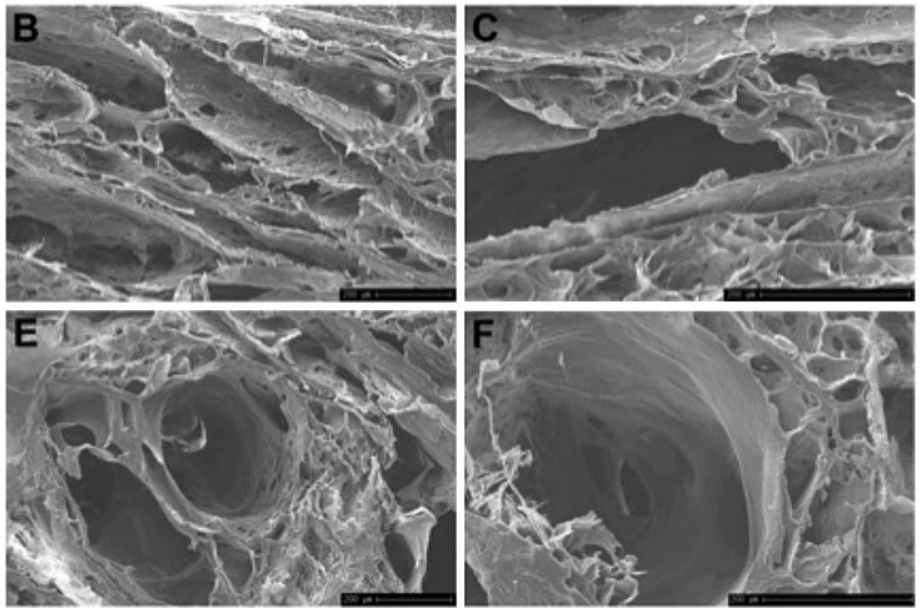

Figure 1. Representative SEM images of the macro-structure of PHB-HV 3D scaffolds produced through emulsion freezing/freeze-drying technique. A) Cross-section of the scaffolds magnified; B) $100 \times$ (porous structure in the middle of the cross-section), scale bar: $200 \mu \mathrm{m} ; C) 200 \times$ (enlarged view of a region in the middle of the cross-section), scale bar: $200 \mu \mathrm{m}$. D) Longitudinal section of the scaffolds magnified; E) $100 \times$ (porous structure in the middle of the longitudinal section), scale bar: $200 \mu \mathrm{m} ; \mathrm{F}$ ) $200 \times(\mathrm{enlarged}$ view of a region in the middle of the longitudinal section), scale bar: $200 \mu \mathrm{m}$. PHB-HV $3 \mathrm{D}$ scaffolds exhibit an anisotropic morphology disclosing both round and laminar pores.

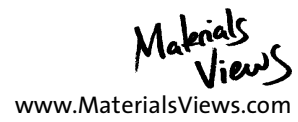

Early View Publication; these are NOT the final page numbers, use DOI for citation !! 

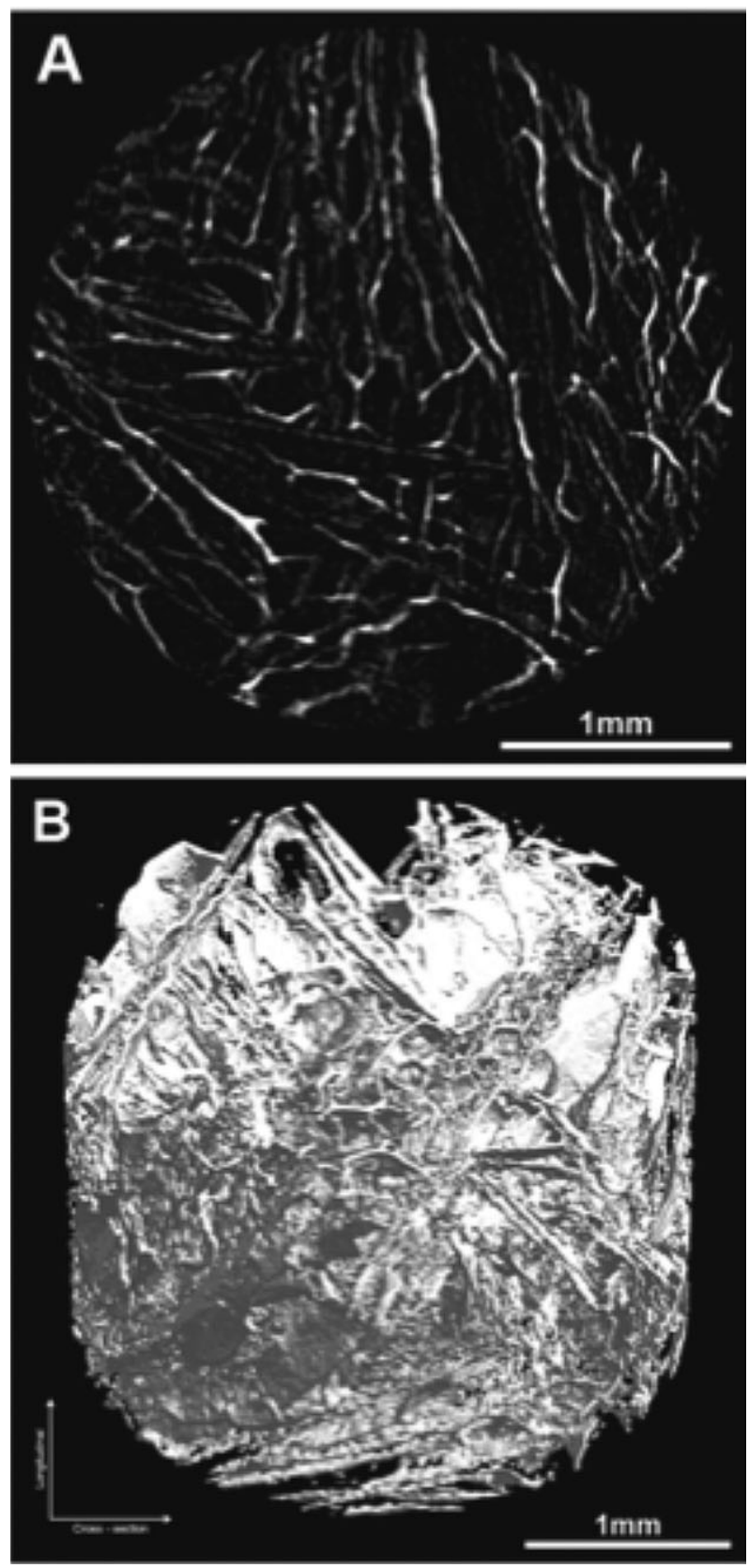

Figure 2. Representative A) $2 \mathrm{D}$ and $\mathrm{B}$ ) $3 \mathrm{D}$ micro- $\mathrm{CT}$ images of PHB-HV $3 \mathrm{D}$ scaffolds produced through emulsion freezing/ freeze-drying technique. These scaffolds display a fully interconnected network of pores with arbitrary shapes, sizes, and directions.

The results concerning hippocampal derived primary cell cultures demonstrated that these cells were able to adhere, to maintain their viability and to proliferate throughout the scaffolds structure (Figure $4 a-c)$. BrdU data showed a progressive decrease in the amount of proliferating cells with time (Figure $4 \mathrm{~d}$ ) along with an initial
Table 1. Compressive mechanical properties of PHB-HV $3 \mathrm{D}$ scaffolds.

\begin{tabular}{lcc} 
Direction & Condition & $\begin{array}{c}\text { Compressive } \\
\text { modulus } \\
\text { [MPa] }\end{array}$ \\
\hline Longitudinal & Dry & $1.4 \pm 0.7$ \\
& Wet & $0.7 \pm 0.2$ \\
Cross-section & Dry & $2.9 \pm 0.3$ \\
& Wet & $0.9 \pm 0.3$
\end{tabular}

slight increase of the total dsDNA present in the scaffolds between days 2 and 7 , followed by its statistically significant decrease $(p<0.001)$ between days 7 and 14 (Figure 4e). Moreover, the MTS test results revealed a progressive increase in the metabolic activity of these cells (Figure 4f).

Primary cultures of cortical glial cells showed that astrocytes and oligodendrocytes were also able to adhere, maintain their viability and proliferate within the scaffolds structure (Figure 5a-i). Throughout the experiment period, a progressive decrease in the amount of proliferating cells with time was registered (Figure $5 \mathrm{j}$ ) regardless of the gradual increase in both the total dsDNA content of the scaffolds (Figure 5k) and cells metabolic activity (Figure 5l).

\subsection{Interaction between Mesenchymal-like Stem Cells and PHB-HV Scaffolds}

All the three distinct types of mesenchymal-like stem cells (MSCs) (HUCPVCs, BM-MSCs, and ASCs) studied demonstrated ability to adhere, to maintain their viability and to proliferate within the scaffolds structure (Figure $6 \mathrm{a}-\mathrm{d}$ ) as previously observed with the CNS-derived cells. All MSCs showed increases in the amount of proliferating cells with time (Figure 6e), in the total dsDNA content within the scaffolds (Figure 6f) and in their metabolic activity (Figure 6g).

Moreover, the comparison between the interactions of the three different types of MSCs with the scaffolds revealed that HUCPVCs presented the greatest increase in total dsDNA (Figure 6f) as already observed in the second day of culture (Figure 6e). However, the greatest increase regarding the metabolic viability was registered for ASCs (Figure 6g).

\subsection{Interaction between OECs and PHB-HV Scaffolds}

The study of the interaction between OECs and the scaffolds showed that these cells, like the other cell types

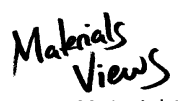

www.MaterialsViews.com
Macromol. Biosci. 2013, DOI: 10.1002/mabi.201300178

(C) 2013 WILEY-VCH Verlag GmbH \& Co. KGaA, Weinheim

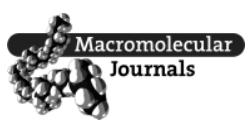

Early View Publication; these are NOT the final page numbers, use DOI for citation !! 


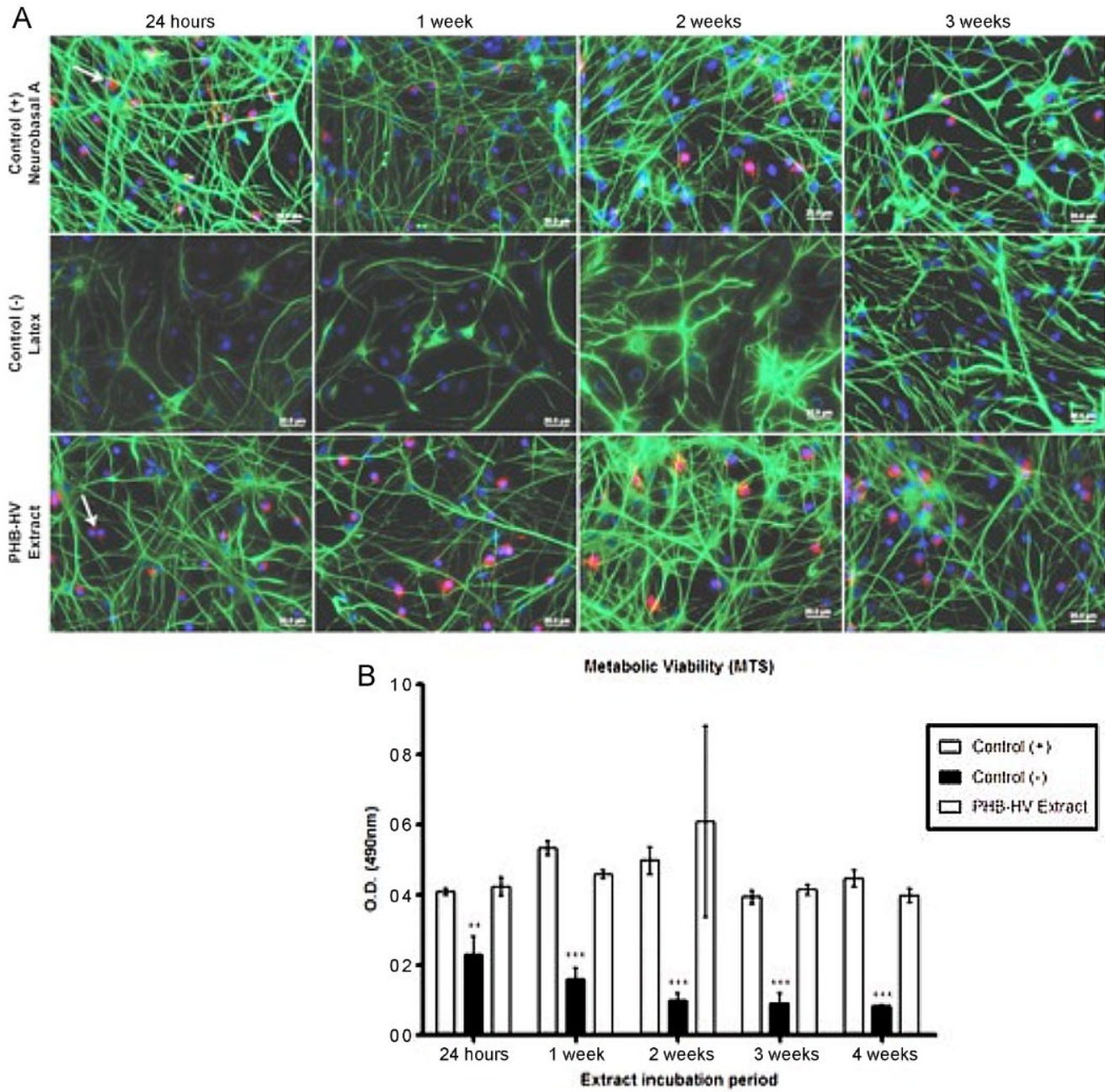

Figure 3. In vitro cytotoxicity evaluation results. Hippocampus derived primary cell cultures after a $72 \mathrm{~h}$ incubation period with extracts containing standard culture medium (positive control for cell viability), latex rubber plus standard culture medium (negative control for cell viability) and PHB-HV scaffolds plus standard culture medium (PHB-HV extract), collected after 1, 7, 14, 21, and $28 \mathrm{~d}$ of extraction. A) Representative fluorescence images showing similar cells densities and morphology between cells grown in the extracts corresponding to positive control and PHB-HV extract, contrasting the results observed for cells grown in negative control extract. Nucleus stained in blue (DAPI), astrocytes stained in green (GFAP) and neurons (some indicated by the arrows) stained in red (MAP2). The scale bar indicates $20.0 \mu \mathrm{m}$. B) MTS test results demonstrating that cells grown in positive control and PHB-HV extracts were able to metabolize MTS in greater extent than cells grown in negative control extract. O.D. read at $490 \mathrm{~nm} .\left({ }^{* *} p<0.01,{ }^{* * *} p<0.001\right.$; two-way ANOVA, $n=5$, mean $\pm S D$ ).

investigated, also adhered, maintained their viability and proliferate within the scaffolds structure (Figure $7 a-c$ ). However, although the ELISA BrdU data demonstrated a significant increase in the amount of proliferating cells between days 2 and 7 (Figure 7d), this was not verified by the dsDNA quantification assay (Figure 7e) which showed a maintenance of the total dsDNA content within the scaffolds. Concerning the metabolic viability assays, the results obtained revealed that these cells maintained their metabolic viability throughout the experiment with a small, but significant, increase between days 7 and 14 (Figure 7f).

\subsection{In Vivo Histocompatibility Evaluation}

\subsubsection{Subcutaneous Implantation}

The scaffolds integration into the host tissue analyzed by H\&E staining revealed that the scaffolds evoked an initial inflammatory response along with the deposition of some collagen fibers in the interface between the scaffold and the adjacent tissue detected after 1 week of implantation (Figure 8a,b). After the fourth week of implantation the initial inflammatory response faded (Figure $8 c, d$ ) and it was possible to detect the presence of blood vessels containing 


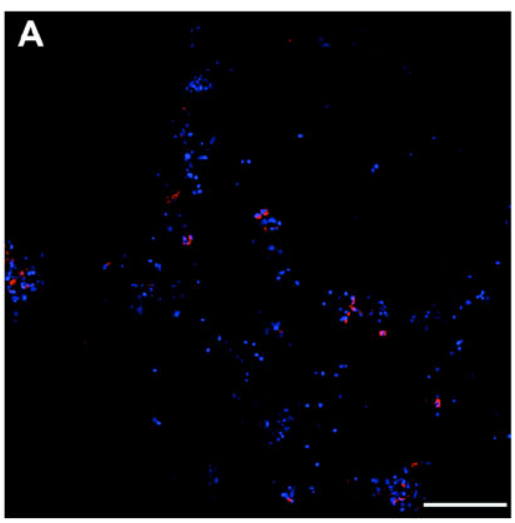

D

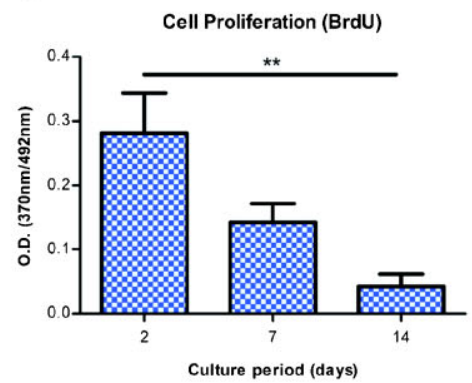

\section{B}

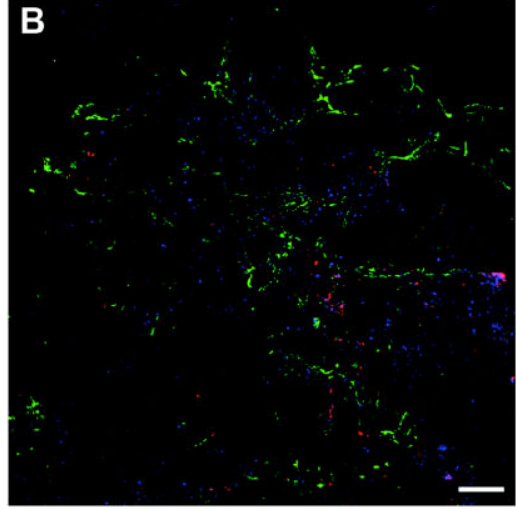

E

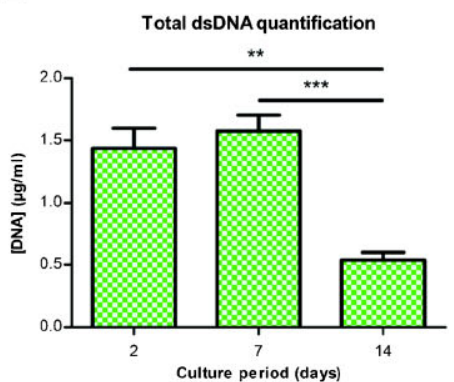

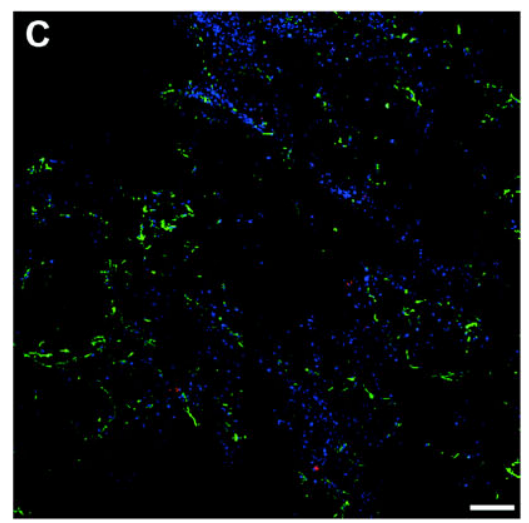

$\mathbf{F}$

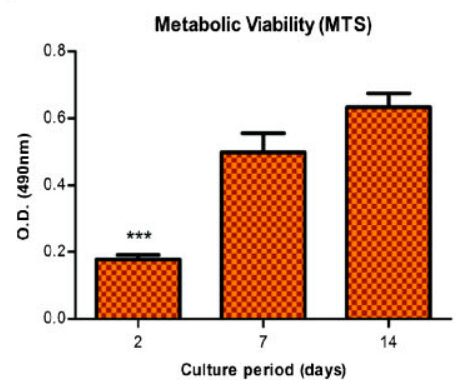

Figure 4. Direct contact assays with hippocampus derived primary cell cultures results. Cells were seeded ( 200000 cells per scaffold) and grown up to $14 \mathrm{~d}$. Representative fluorescence images showing a central area of scaffolds seeded with hippocampus derived primary cell cultures evidencing that these cells were able to adhere, maintain their viability and proliferate throughout the scaffolds structure after A) $2 \mathrm{~d}, \mathrm{~B}) 7 \mathrm{~d}$, and C) $14 \mathrm{~d}$ in culture. Nucleus stained in blue (DAPI), astrocytes stained in green (GFAP) and neurons stained in red (MAP2). The scale bar indicates $100 \mu \mathrm{m}$. D) ELISA BrdU data demonstrating a progressive decrease in the amount of proliferating cells over time. O.D. read at $370 \mathrm{~nm} / 492 \mathrm{~nm}$. E) Total dsDNA quantification data revealing a non-statistically significant increase on dsDNA content between days 2 and 7, followed by its significant decrease between days 7 and 14. F) MTS test results showing a progressive increase in cells metabolic activity over time. O.D. read at $490 \mathrm{~nm}$. $\left({ }^{* *} p<0.01,{ }^{* * *} p<0.001\right.$; one-way ANOVA, $n=5$, mean \pm SD).

circulating erythrocytes inside the scaffolds, deposition of connective tissue throughout the scaffolds structure and some scattered areas containing a few macrophages (Figure 8d, some macrophages indicated by the black arrows). Moreover, there was no evidence of necrotic tissue and it was possible to observe some scaffold degradation when compared to the data obtained for week 1 (Figure 8a-d).

Twelve weeks after implantation it was possible to observe an increase in the amount of connective tissue contained inside the scaffolds and the presence of blood vessels. At this time point it was also possible to observe that PHB-HV scaffolds degradation occurred along with an apparent reduction of the scaffolds structure volume. A thin capsule of connective tissue surrounding the scaffolds had meanwhile disappeared and, as for the other time points, there was still no evidence of necrotic tissue (Figure 8e,f).

\subsubsection{Hemisection Rat Model of SCI}

The effects of scaffolds integration into the damaged spinal cord tissue was scrutinized by locomotor function evaluation and histological characterization. The left hindlimb motor function evaluation began on week 1 after surgery and continued weekly for 1 month. The identity of the animals was kept blind to the observer in all the experiments.

The BBB test data revealed no statistical significant differences between the left hindlimb function of control and PHB-HV groups throughout the testing period (Figure 9a). Four weeks after surgery animals from both experimental groups were able to extensively move at least two joints of the left hindlimb $(3.75 \pm 1.5$ in the $\mathrm{BBB}$ score). This observation suggests that the presence of the PHB-HV scaffolds did not lead to either an improvement or worsening of the left hindlimb motor function recovery.

Hematoxylin and eosin (H\&E) staining was performed to assess the effects of PHB-HV scaffolds implantation on the spinal cord tissue organization, surrounding tissue infiltration, and axon vacuolization after SCI. The analyses of coronal median cord sections showed that 4 weeks after surgery the tissues in which PHB-HV scaffold had been implanted (Figure 9c) presented higher quantity of cells on

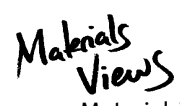

www.MaterialsViews.com
Macromol. Biosci. 2013, DOI: 10.1002/mabi.201300178

(C) 2013 WILEY-VCH Verlag GmbH \& Co. KGaA, Weinheim

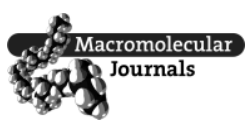

Early View Publication; these are NOT the final page numbers, use DOI for citation !! 
2 days

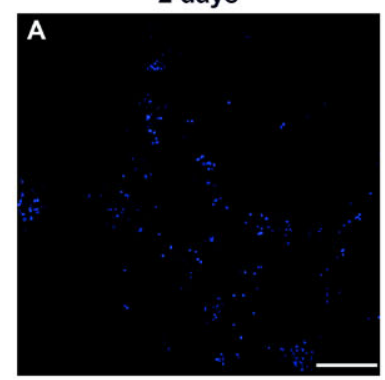

D

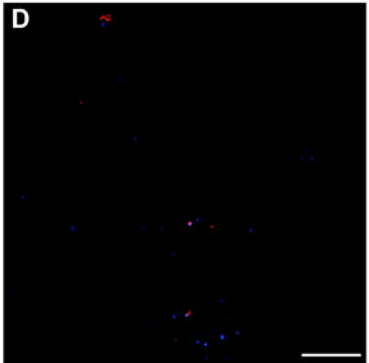

G

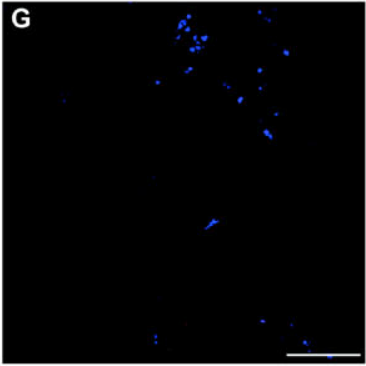

7 days
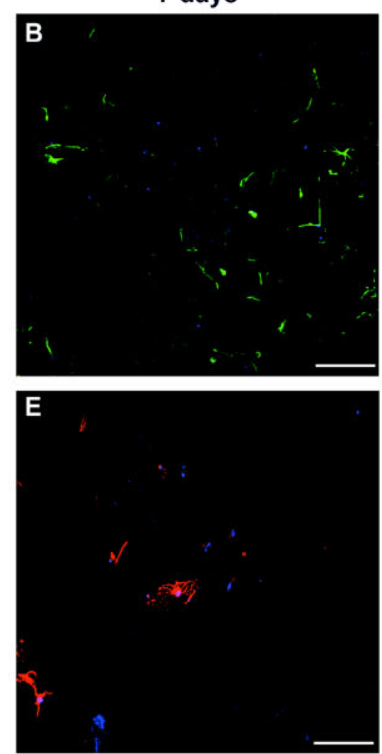

H

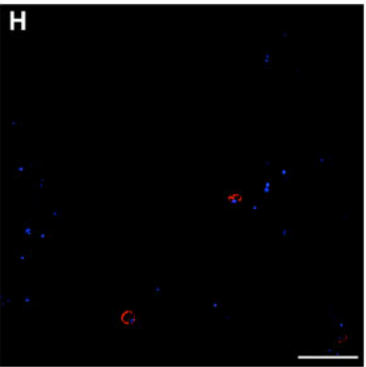

14 days
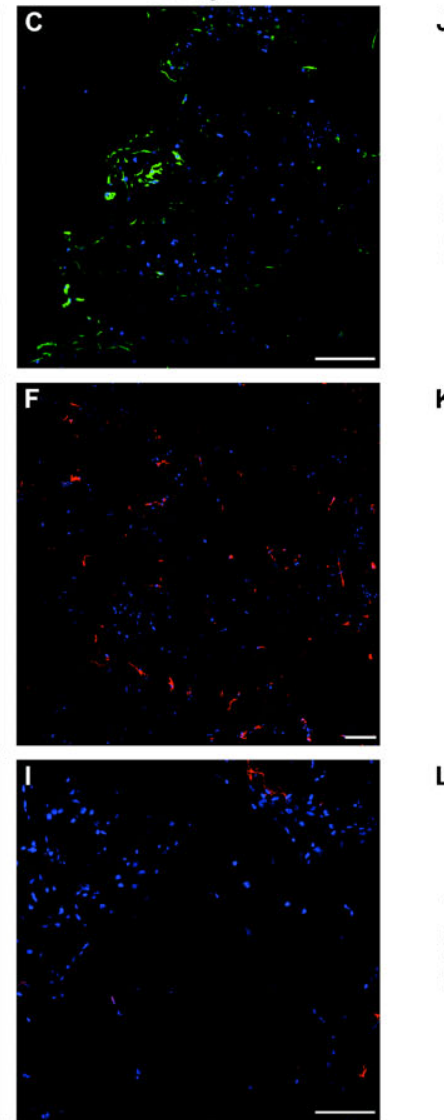

$\checkmark$

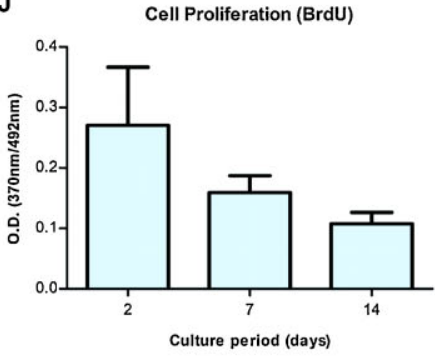

K

Total dsDNA quantification

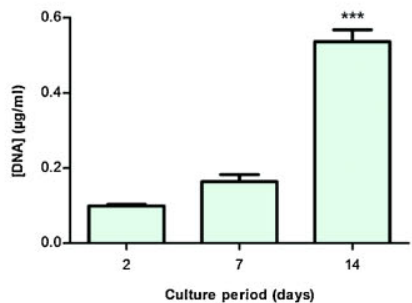

L

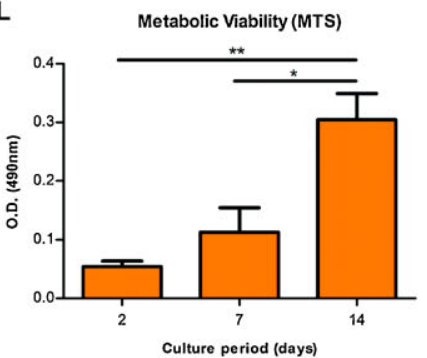

Figure 5. Direct contact assays with primary cultures of cortical glial cells results. Cells were seeded (200 ooo cells per scaffold) and grown up to $14 \mathrm{~d}$. Representative fluorescence images presenting a central area of scaffolds seeded with primary cultures of cortical glial cells revealing that these cells were also able to adhere, maintain their viability and proliferate throughout the scaffolds structure over time. Astrocytes stained in green (GFAP) after A) $2 \mathrm{~d}, \mathrm{~B}) 7 \mathrm{~d}$, and C) $14 \mathrm{~d}$ in culture. Oligodendrocytes stained in red (O4) after a D) $2 \mathrm{~d}, \mathrm{E}) 7 \mathrm{~d}$, and F) $14 \mathrm{~d}$ in culture. Microglia cells stained in red (CD11b) after a G) $2 \mathrm{~d}, \mathrm{H}$ ) $7 \mathrm{~d}$, and I) $14 \mathrm{~d}$ in culture. Nucleus stained in blue (DAPI). The scale bar indicates $100 \mu \mathrm{m}$. J) ELISA BrdU data showing a progressive decrease in the amount of proliferating cells over time. O.D. read at $370 \mathrm{~nm} / 492 \mathrm{~nm}$. K) Total dsDNA quantification data revealing a non-statistically significant increase on dsDNA content between days 2 and 7, followed by its significant decrease between days 7 and 14. L) MTS test results demonstrating a progressive increase in cells metabolic activity over time. O.D. read at $490 \mathrm{~nm}$. $\left({ }^{*} p<0.05,{ }^{* *} p<0.01,{ }^{* * *} p<0.001\right.$; one-way ANOVA, $n=4$, mean \pm SD).

the left side of the cord when compared with the right side. Moreover, it was possible to detect the presence of blood vessels and collagen fibers with some degree of alignment in some peripheral areas of the scaffold. Additionally, occurrence of vacuolization on the left side of the cord compared to the right side was observed. Neutrophils and macrophages were detected. Moreover, there was also evidence of some fibrosis in the scaffolds peripheral area subjacent to the vertebral cord. Finally, no necrotic tissue was observed.

The same analyses performed in coronal median cord sections of the control group (Figure $9 \mathrm{~b}$ ) revealed some inflammation in the vicinity of the lesion along with few fibrosis and the presence of blood vessels. There was also evidence of vacuolization; however, this seemed to be confined to the area surrounding the lesion. Furthermore, it was possible to observe intact neurons in the vicinity of the lesion.

\section{Discussion}

\subsection{PHB-HV Scaffolds Characterization}

In order to guide tissue development and organization into a mature and healthy state, biomaterial scaffolds must exhibit desirable physical characteristics which include biocompatibility, adequate mechanical properties, high porosity, large surface area, adequate pore size, interconnected porous structures, and biodegradability. ${ }^{[19,52,53]}$ Our results demonstrated that freeze-drying 

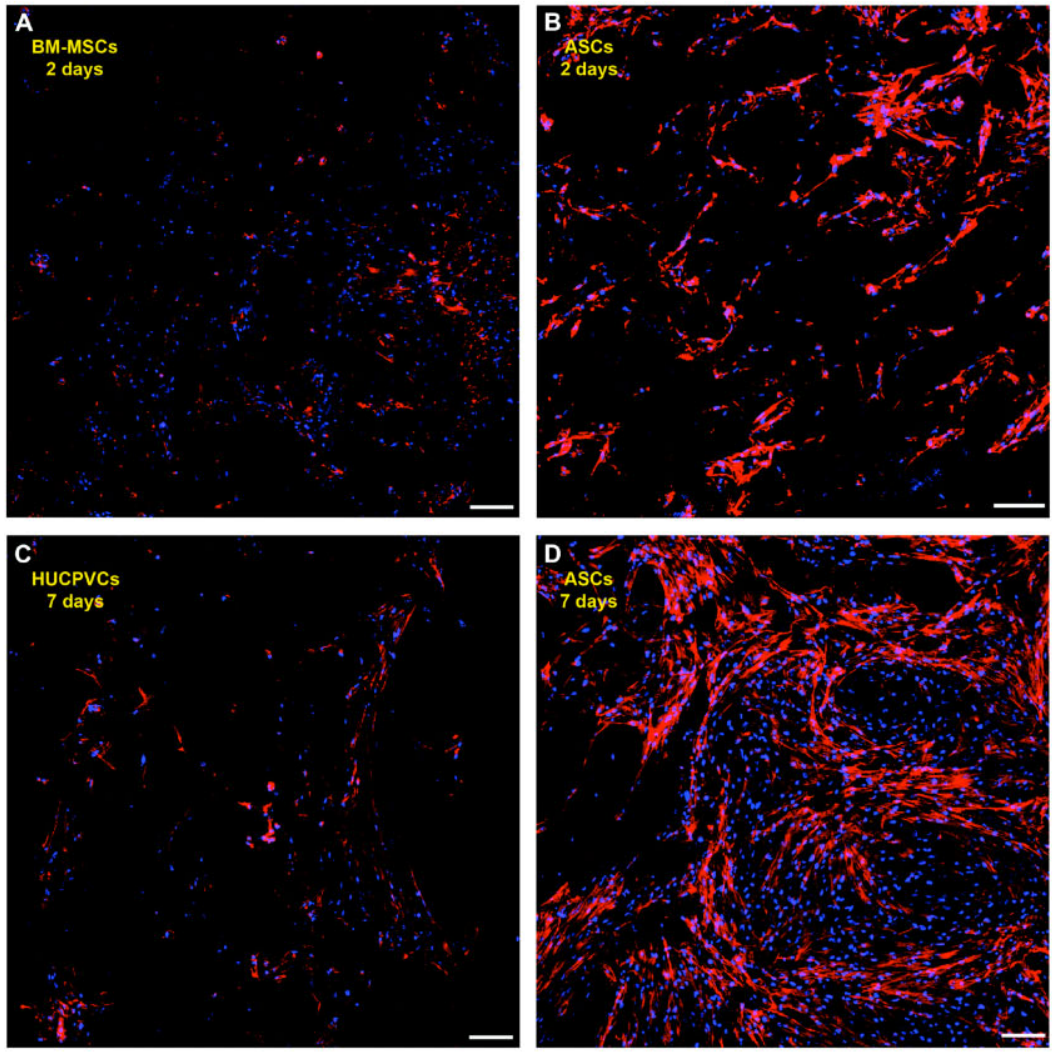

E

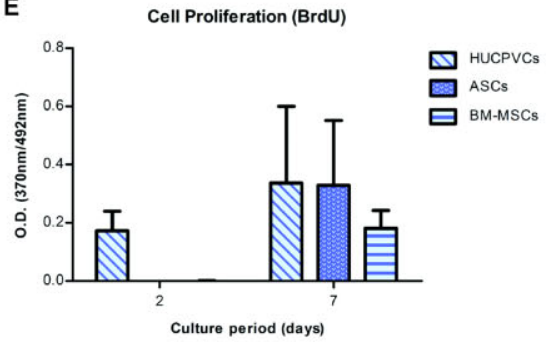

F

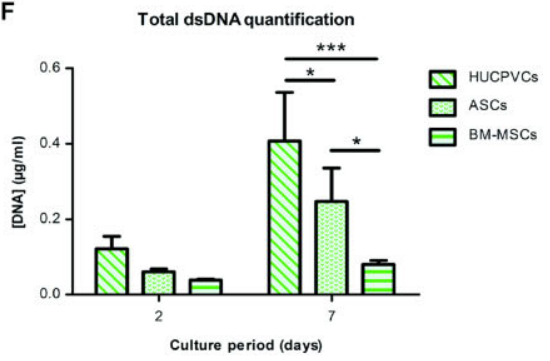

G

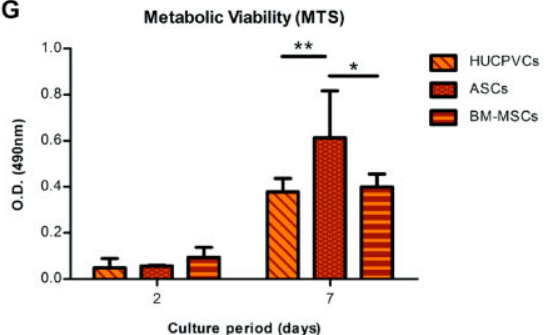

Figure 6. Direct contact assays with mesenchymal-like stem cells (MSCs) from distinct sources (HUCPVCs, BM-MSCs, and ASCs). Cells were seeded (50 ooo cells per scaffold) and grown up to $7 \mathrm{~d}$. A-D) Representative fluorescence images showing a central area of scaffolds seeded with MSCs demonstrating that all distinct cell-types were able to adhere, maintain their viability and proliferate throughout the scaffolds structure during culture period. Nucleus stained in blue (DAPI) and F-actin filaments stained in red (phalloidin). The scale bar indicates $100 \mu \mathrm{m}$. E) ELISA BrdU data unveiling an increase in the amount of proliferating cells between days 2 and 7 registered for all cell-types. HUCPVCs proved to be already well established by the 2 nd day in culture. O.D. read at $370 \mathrm{~nm} / 492 \mathrm{~nm}$. F) Total dsDNA quantification data revealing a significant increase on dsDNA content between days 2 and 7 also observed for all MSCs, being the greatest increase registered for HUCPVCs. G) MTS test results showing an increase in all MSCs metabolic activity over time, especially for ASCs. O.D. read at $490 \mathrm{~nm}$. $\left({ }^{*} p<0.05,{ }^{* *} p<0.01,{ }^{* * *} p<0.001\right.$; two-way ANOVA, $n=3$, mean $\left.\pm \mathrm{SD}\right)$.

processing technique allowed the production of scaffolds based on PHB-HV polymer that revealed an interconnected network of open pores exhibiting arbitrary shapes, sizes, and directions as previously reported by Sultana and Wang. ${ }^{[39]}$ Moreover, the developed scaffolds present high porosity, large pore sizes, and anisotropic characteristics which influence its mechanical behavior.

The results herein presented also showed that the developed scaffolds exhibit laminar pores with some degree of alignment on its cross-section direction. In the freeze-drying process, the polymeric solution is frozen allowing to create an interpenetrating network of ice crystal that are further removed by sublimation. The scaffolds herein described were previously prepared in a petri dish with $90 \mathrm{~mm} \times 15 \mathrm{~mm}$ and just further cut in smaller cylindrical pieces $(4 \mathrm{~mm}$ in diameter and $5 \mathrm{~mm}$ in height). The introduction of a unidirectional temperature gradient-resulting from the high ratio between diameter and height of the frozen sample-during the freezing phase induced the formation of laminar pores in the direction of this gradient.

Though, this was not enough to promote the aligned guidance of tissue deposition within the scaffolds structure, this may be possible in future developments by using the methodology recently described by Davidenko et al. ${ }^{[5]}$ Additionally, a reported rough estimation of modulus values for human spinal cord tissue was 1.02$1.37 \mathrm{MPa},{ }^{[55,56]}$ and $0.0288 \mathrm{MPa}$ for the adult rat spinal cord. ${ }^{[53]}$ Comparing these modulus values to the ones obtained for the PHB-HV scaffolds (0.7-0.9 MPa in the wet state), it is possible to assert that from a biomechanical

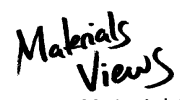

Macromol. Biosci. 2013, DOI: 10.1002/mabi.201300178 


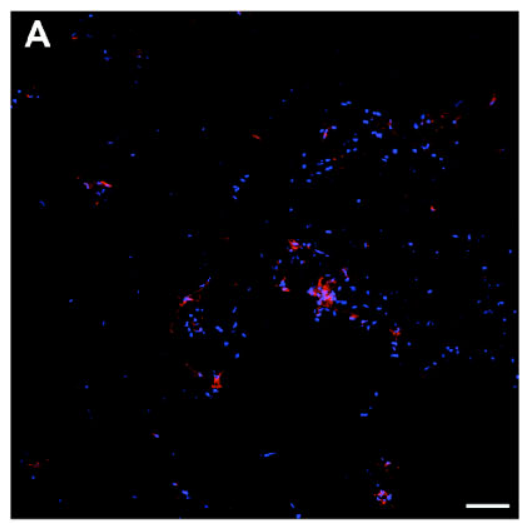

D

Cell Proliferation (BrdU)

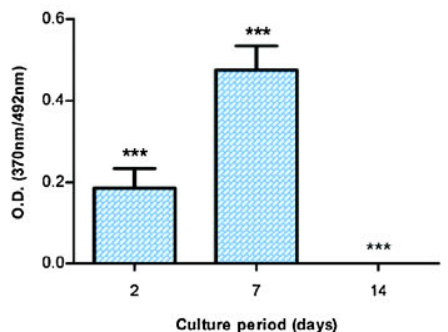

B

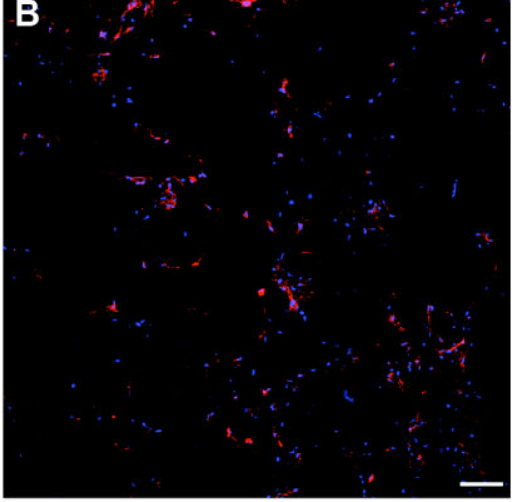

E

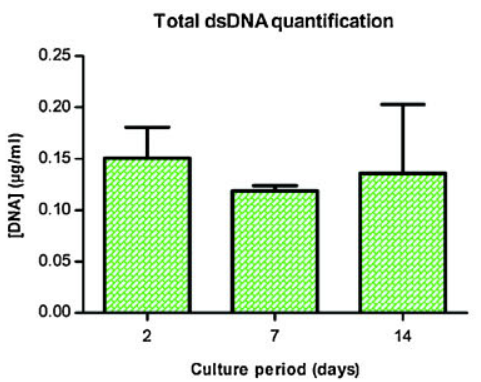

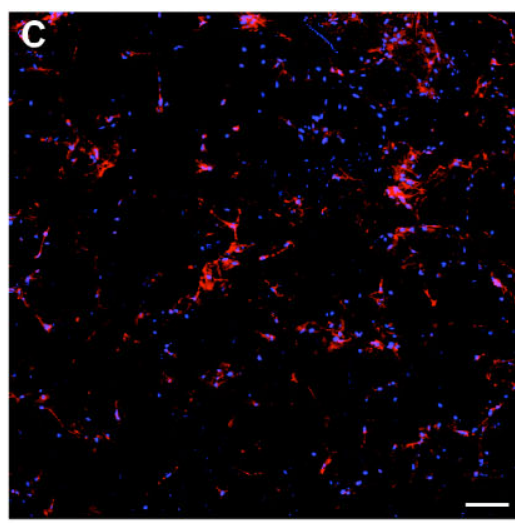

$\mathbf{F}$

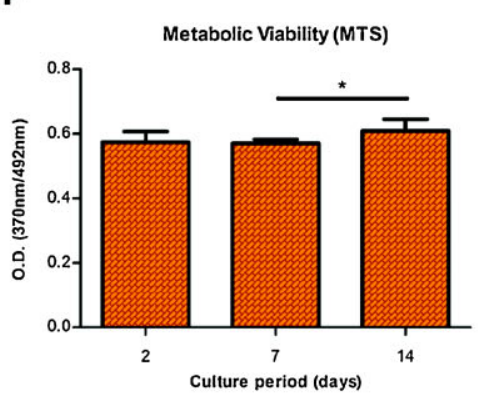

Figure 7. Direct contact assays with OECs. Cells were seeded (200 ooo cells per scaffold) and grown up to $14 \mathrm{~d}$. Representative fluorescence images showing a central area of scaffolds seeded with OECs cultures showing that these cells were able to adhere, maintain their viability, and proliferate throughout the scaffolds structure after A) $2 d, B$ ) $7 d$, and C) $14 d$ in culture. Nucleus stained in blue (DAPI) and F-actin filaments stained in red (phalloidin). The scale bar indicates $100 \mu \mathrm{m}$. D) ELISA BrdU data demonstrating a statistically significant increase in the amount of proliferating cells between days 2 and 7 in culture followed by its significant decrease between days 7 and 14. O.D. read at $370 \mathrm{~nm} / 492 \mathrm{~nm}$. E) Total dsDNA quantification data revealing maintenance of the total dsDNA content over time. F) MTS test results showing maintenance of cells metabolic activity over time. O.D. read at $490 \mathrm{~nm}$. ( ${ }^{*} p<0.05,{ }^{* * *} p<0.001 ;$ one-way ANOVA, $n=4$, mean $\pm S D)$.

point of view the developed scaffolds may be suitable for SCI treatment in humans.

In vitro cytotoxicity assessments allowed the evaluation of the potential toxic effect of biomaterials on cells. ${ }^{[57]}$ These are commonly performed using cell lines. However, the genetic instability and alteration in growth characteristics (anchorage independence, loss of contact inhibition, and density limitation of growth) that is often observed in these types of cell cultures limits the extrapolation of in vitro data to the in vivo conditions. ${ }^{[58]}$ Primary cultures on the other hand, in addition to its biological significance, are capable of maintaining their tissue specific markers and retain their special function which allows a more reliable extrapolation between the in vitro data and in vivo conditions. ${ }^{[59]}$ Considering the aim of these structures, we found critical to perform the same assessment using CNS-derived primary cell cultures in order to ascertain the toxic effect that the developed scaffolds could exhibit over these cells. Our results clearly demonstrated that the degradation products of the PHB-HV scaffolds do not affect the metabolic activity of hippocampal-derived cells. For all time points there were no significant differences between MTS metabolization by the positive control cells and the same reduction performed by the cells from the PHB-HV extract. On the other hand, the results of the negative controls clearly evidence a cytotoxic effect over the cells. Therefore, these results were supportive of a lack of cytotoxic effect of these structures.

\subsection{Direct Contact Assays}

Neuroregeneration after SCI requires axonal outgrowth of existing and new axons along with their myelination. In this sense, to be considered suitable for SCI repair PHB-HV scaffolds must be able to support the growth of CNS-derived cells (neurons and glial cells) in its structure. For this purpose direct contact assays were performed to evaluate and predict the interaction between CNSderived cells (neurons and gial cells) and PHB-HV scaffolds. The data obtained concerning cell proliferation in hippocampal-derived primary cell cultures showed that over time there was a continuous decrease in the amount of 

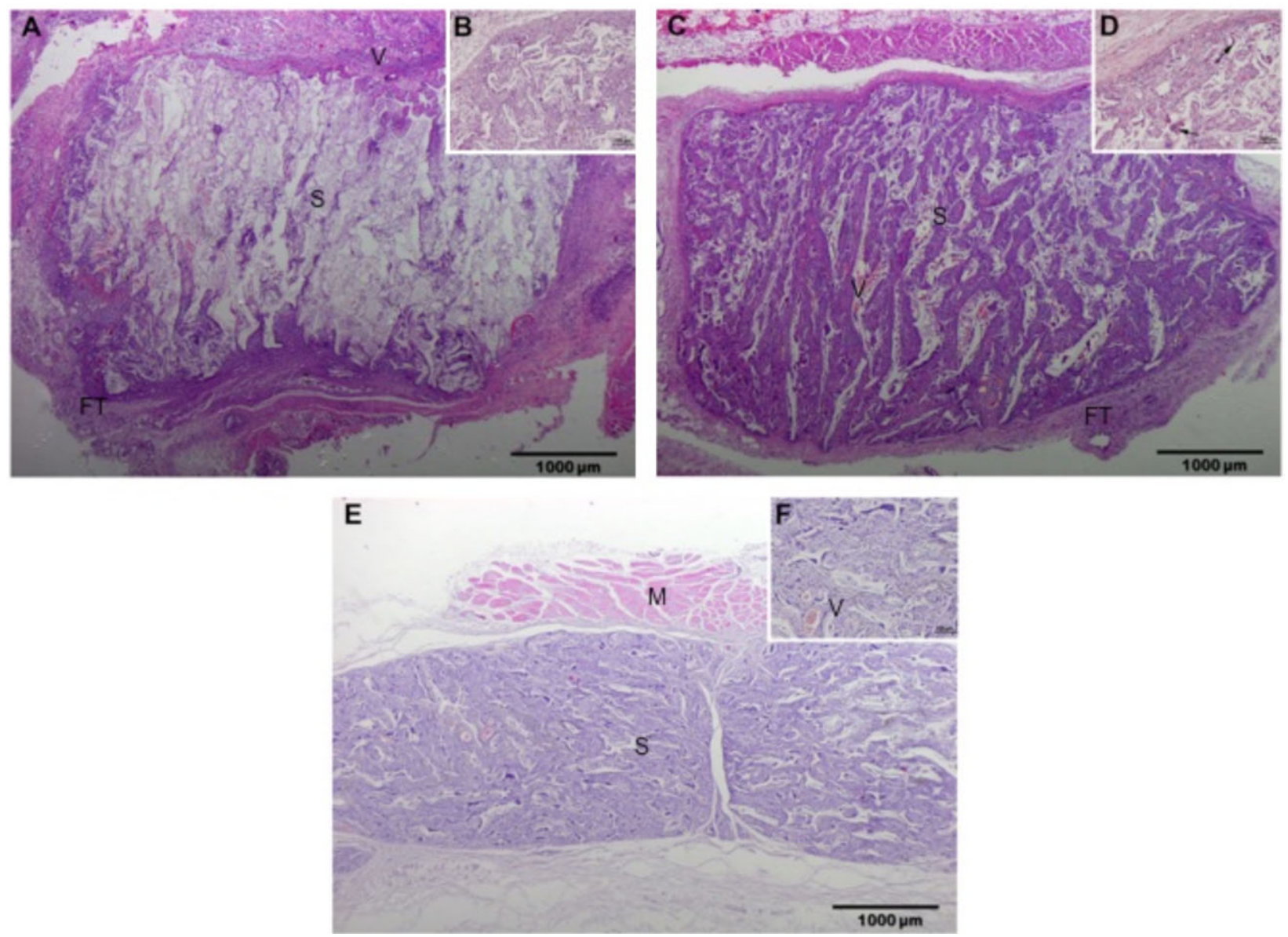

Figure 8. In vivo tissue response to PHB-HV 3 D scaffolds subcutaneous implantation. Histological sections were stained with $\mathrm{H} \& \mathrm{E}$. After A,B) 1 week, C,D) 4 weeks, and E,F) 12 weeks of subcutaneous implantation, the tested PHB-HV 3 D scaffolds were well integrated within the surrounding tissue with minimal inflammatory response. (FT: fibrous tissue; M: muscle; S: PHB-HV scaffolds infiltrated by cells; V: blood vessels.)

cells that were proliferating (BrdU-statistically significant between the $2^{\text {nd }}$ and $14^{\text {th }}$ day) in culture. These results may be explained by the presence of neural progenitor cells ${ }^{[60]}$ or astrocytes, which as described before are also present in this culture systems. ${ }^{[61]}$ This explanation may also justify the slight increase in the amount of dsDNA contained in the scaffolds registered between the $2^{\text {nd }}$ and $7^{\text {th }}$ day in culture (Figure 4e). Moreover, the statistically significant decrease in the amount of dsDNA observed between the $7^{\text {th }}$ and $14^{\text {th }}$ day in culture could be related to cell confluence in the scaffolds that may have led to cell death and subsequent DNA fragmentation. ${ }^{[43]}$ These observations are supported by the immunocytochemistry results which showed that during the three periods in culture, these cells were able to adhere to the scaffolds surface, maintain their viability and proliferate throughout the scaffold in an apparently uniform manner, over time. However, between the $7^{\text {th }}$ and $14^{\text {th }}$ day in culture there was a decrease in specific staining (GFAP and MAP2) supporting the hypothesis of death mediated by cell confluence. Concerning the metabolic activity of these cells, MTS test results showed a progressive increase in their metabolic activity that proved to be statistically significant between both $2^{\text {nd }}-7^{\text {th }}$ day and $2^{\text {nd }}-14^{\text {th }}$ day in culture. Additionally, contrary to what was stated by Capasso ${ }^{[44]}$ these experiments demonstrate that the values obtained for the MTS test (or similar tests) do not always correlate with the total number of living cells. Therefore one must consider that MTS requires adjuvant cell analyses techniques to evaluate cell viability.

Regarding primary cultures of cortical glial cells, the progressive decrease in the amount of proliferating cells (BrdU) can be explained by an increase in the total number of cells over time that lead to a reduction of the surface area available for the expansion of other migrating cells, thus causing a decrease in the amount of cells that were proliferating. This observation is supported by the dsDNA quantification which showed a continuous increase in the

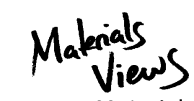

www.MaterialsViews.com
Macromol. Biosci. 2013, DOI: 10.1002/mabi.201300178

(C) 2013 WILEY-VCH Verlag GmbH \& Co. KGaA, Weinheim

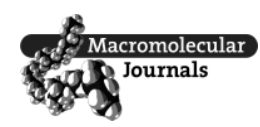

Early View Publication; these are NOT the final page numbers, use DOI for citation !! 

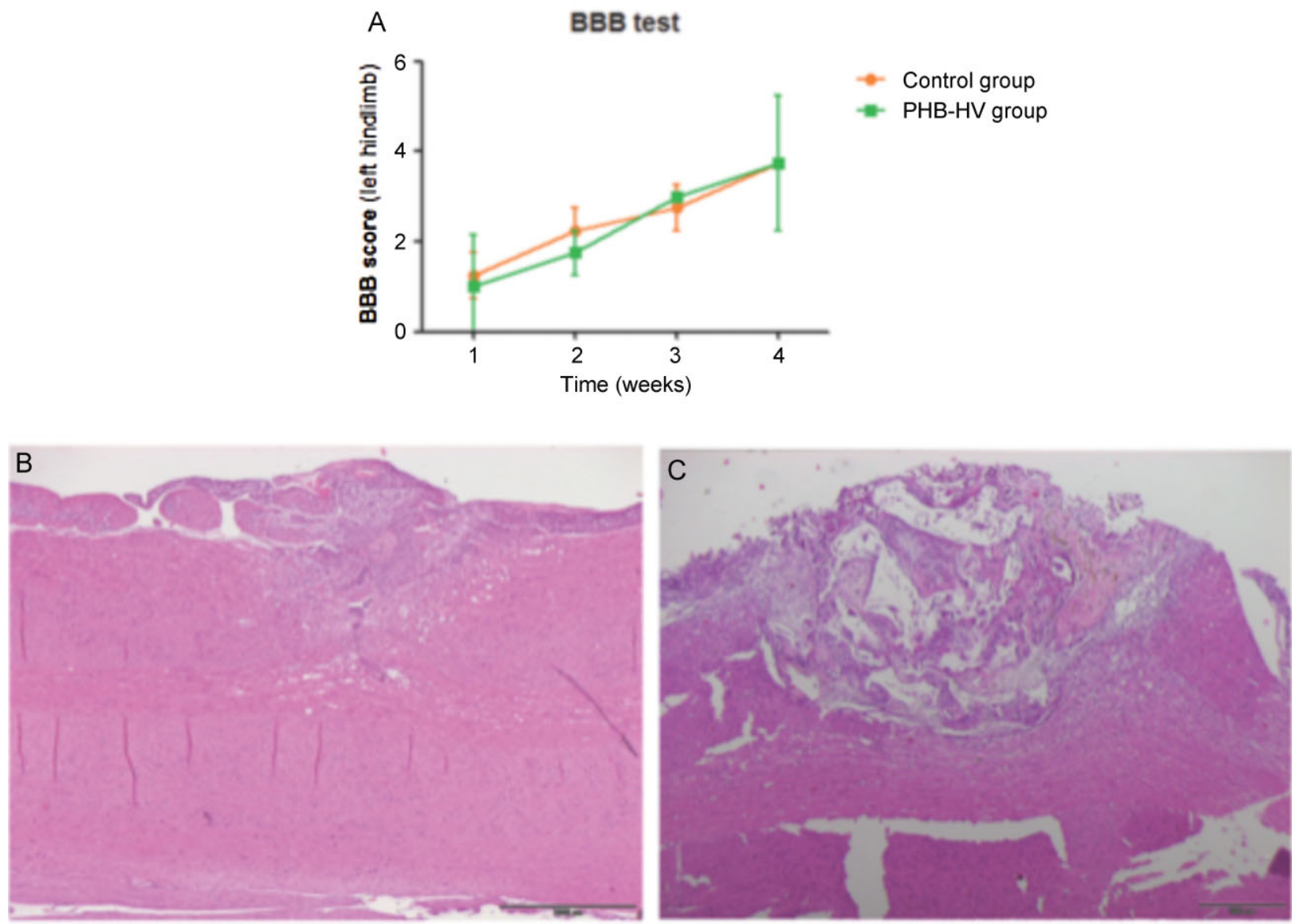

Figure 9. In vivo tissue response to $\mathrm{PHB}-\mathrm{HV}{ }_{3} \mathrm{D}$ scaffolds implantation in a hemisection rat model of $\mathrm{SCl}$. A) Left hindlimb locomotor function recovery evaluation through $B B B$ test. The data revealed no statistical significant differences between the left hindlimb function of control and PHB-HV groups throughout the testing period. Histological sections of the coronal median cord subdivision were stained with $\mathrm{H} \& \mathrm{E}$. After 4 weeks, the control group (B) revealed a higher peripheral tissue infiltration when compared to animals in which PHB-HV scaffold was implanted following spinal cord injury (C).

amount of dsDNA contained in the scaffolds. Furthermore, the immunocytochemistry results revealed that during the three periods in culture, glial cells were also able to adhere to the scaffold surface, to maintain their viability and to proliferate throughout the length of the scaffold. Additionally, this set of data unveils the ability of these scaffolds to support the in vitro culture of CNS-derived cells attesting its biocompatibility with these cell types.

MSCs have the potential for self-renewal, multipotency, migratory behavior to areas of damage and inflammation, exhibit site-dependent differentiation in response to environmental signals, and the ability to exert paracrine effects on other cells that include immunomodulation, trophic, anti-scarring, and chemoattractant effects. ${ }^{[62,63]}$ Moreover, it has been suggested that MSCs secretome may play a role in potentiating neural progenitors proliferation, as well as neuronal survival/differentiation. ${ }^{[46,64-66]}$ In this sense, the strategy that we propose concerns the combination of PHB-HV-based scaffolds with MSCs in order to overcome some of the barriers to regeneration that arise from an SCI. Our results revealed not only the ability of the studied MSCs to adhere, maintain their viability and proliferate within the scaffolds structure, but also pointed out the higher proliferative potential of HUCPVCs over BM-MSCs. These observations are supported by the results obtained by Baksh et al. ${ }^{[67]}$ in a study where the authors compared the proliferative and multilineage differentiation potential of HUCPVCs and BM-MSCs. Furthermore, our study also showed that ASCs demonstrated a higher proliferative potential when compared with BM-MSCs, being this result supported by the observations described by Kern et al. ${ }^{[68]}$ in their comparative analysis of BM-MSCs, UCB-MSCs (umbilical cord blood mesenchymal-like stem cells) and ASCs. Moreover, our experiments pointed toward a higher proliferative potential of HUCPVCs comparatively to ASCs. Lastly, these data revealed the ability of these scaffolds to support the in vitro culture of HUCPVCs, BMMSCs, and ASCs demonstrating its biocompatibility with 
these cell types and their potential as carriers for delivering stem cells to the injury site.

OECs derived from the olfactory bulb are claimed to be suitable candidates for cell-mediated repair following SCI due to their reported ability to promote axonal regeneration, remyelination, migrate within the CNS and coexist in an astrocyte-rich environment and therefore fully integrate within a lesion, ${ }^{[69]}$ as well as to promote functional recovery following various types of SCI. ${ }^{[70-76]}$ Our results demonstrated that OECs were also able to adhere to the scaffolds structure, maintaining their viability and proliferation throughout the its scaffolds structure. However, the analysis of their proliferation profile reveals different results regarding the ELISA BrdU assay and the total dsDNA quantification revealing an increase in the amount of cells that were proliferating in the $24 \mathrm{~h}$ prior to the ELISA BrdU assay between the $2^{\text {nd }}$ and $7^{\text {th }}$ day in culture, accompanied by the maintenance of the total amount of dsDNA present within the scaffolds in the same period. This observation suggests that although cells did proliferate over time, some of them may have undergone cell death in an extent that somehow prevailed over cell proliferation. Furthermore, maintenance of the total amount of dsDNA seems to be accompanied by maintenance of the metabolic activity throughout time.

These data attests, once more, the biocompatibility of PHB-HV scaffolds and shows the versatility of these structures as carriers for delivering different cell populations relevant for SCI regeneration.

\subsection{Histocompatibility of PHB-HV Scaffolds}

Implantable biomaterials are in direct and sustained contact with the tissues and some of them degrade in situ. Therefore, both the material itself and its degradation products must be devoid of toxicity. ${ }^{[77]}$ As a preliminary assessment of PHB-HV scaffolds histocompatibility, we implanted the scaffolds subcutaneously in Wistar rats and extirpated them after 1, 4, and 12 weeks. Our results showed that the scaffolds were well tolerated by the tissue. After the initial acute inflammation, no abscess formation or tissue necrosis was observed in tissues adjacent to the implanted scaffolds. Moreover, although we observed the deposition of a thin layer of connective tissue encapsulating the scaffolds which vanished over time, this does not attest the non-biocompatibility of these structures and can be considered as a normal response. ${ }^{[78]}$ According to Mikos et al. ${ }^{[79]}$ even in the case of a material compatible with the host tissue, the restitution of normal tissue structure usually observed following an implantation and wound healing does not trail the normal pathway. Additionally, Fournier et al. ${ }^{[77]}$ stated that the body reaction to nearly all materials considered biocompatible in their application is similar, involving their engulfment in an avascular collagenous bag. On the other hand, considering the TE/Cell-based combinatorial approach that we propose, the fibrous capsule surrounding the scaffolds is also an important factor since it influences cell viability: the more blood vessels it contains, the more nutrients reach cells, and better is the systemic delivery of the molecules secreted by them. ${ }^{[80]}$ Additionally, the apparent reduction of the scaffolds structure volume observed at the 12 weeks' time point is probably related with the in vivo degradation rate of the scaffolds. In a recent study, Sultana and Khan ${ }^{[81]}$ claim that the nonspecific esterase and lysozyme enzymes secreted by the immune system cells catalyze the faster in vivo degradation of PHB-HV when compared with its in vitro hydrolysis rate at the same temperature and $\mathrm{pH}$. Moreover, it has been reported that polyhydroxyalkanoates (PHAs) undergo surface erosion. ${ }^{[82]}$ Therefore, a detailed observation of the scaffolds structure shape at the referred time point suggests that the degradation process had a greater impact on the scaffolds surface leading to a reduction on the scaffolds structure volume.

The in vivo histocompatibility evaluation regarding a hemisection rat model of SCI revealed that the tissue damage extension between control and PHB-HV groups was similar. In the PHB-HV group the deleterious effects of the injury seemed to be confined to the primary lesion, evidencing a reduced peripheral tissue infiltration when compared to the control group observations. This evidence suggests that the PHB-HV scaffold was possibly acting as a physical barrier that isolated the peripheral inflammatory process from the one occurring within the nervous tissue. Therefore, since the results herein presented concern a 4 weeks period assessment one can expect that at a longer term, the presence of PHB-HV scaffolds could be important to restrain the deleterious effects mediated by the peripheral inflammatory response over the nervous tissue regeneration process. Furthermore, the inflammation observed on the PHB-HV group was decreased when compared to the one observed for the subcutaneous implants. Nevertheless this inflammatory response did not seem to have a negative impact in the left hindlimb locomotor function recovery as demonstrated by the BBB test results. Additionally, as the strategy we propose involves the combination of the developed PHB-HV scaffolds with MSCs to assist the SCI regeneration process, improved outcomes can be expected namely due to the immunomodelatory and neuroprotective character of these cells.

\section{Conclusion}

The present study explored freeze-drying, as a processing methodology, for the production of scaffolds based on PHB-HV polymer. The scaffolds obtained revealed an

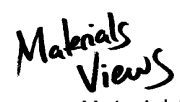

www.MaterialsViews.com
Macromol. Biosci. 2013, DOI: 10.1002/mabi.201300178

(C) 2013 WILEY-VCH Verlag GmbH \& Co. KGaA, Weinheim

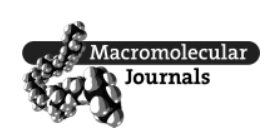


interconnected network of open pores with high porosity, large pore sizes, and anisotropic characteristics which positively influence its mechanical behavior. Furthermore, the cytotoxicity assessment unveiled the lack of a cytotoxic effect of these scaffolds over hippocampus derived primary cell cultures. Direct contact assays revealed the ability of these structures to support the in vitro culture of CNSderived cells and distinct types of MSCs (HUCPVCs, BMMSCs, and ASCs) attesting both its biocompatibility and their potential as carriers for delivering MSCs to the injury site. Lastly, the histocompatibility studies showed that PHB-HV 3D scaffolds were well tolerated by the host tissue revealing vascularization within the scaffolds structure and no evidence of abscess formation or tissue necrosis.

Acknowledgments: This study was supported by the Portuguese Foundation for Science and Technology (FCT; Grant no PTDC/ SAU-BMA/114059/2009; PEst-C/SAU/LA0001/2013-2014 and RNEM-REDE/1506/REM/2005) and Foundation Calouste Gulbenkian, under the scope of the Gulbenkian Program to Support Cutting Edge Research in Life Sciences (A.J.S.). This work was also partially supported by the European FP7 Project Find and Bind (NMP4-SL-2009-229292). The authors would like to thank Miguel Carvalho, Fábio Teixeira, and Filipa Campos for their collaboration in in vivo experiments.

Received: April 5, 2013; Revised: June 26, 2013; Published online: DOI: $10.1002 /$ mabi.201300178

Keywords: biocompatibility; cell-based therapy; PHB-HV 3D scaffolds; spinal cord injury regeneration; tissue engineering

[1] A. Samadikuchaksaraei, J. Neuroeng. Rehabil. 2007, 4, 15.

[2] C. T. Liverman, B. M. Altevogt, J. E. Joy, R. T. Johnson, Spinal Cord Injury: Progress, Promise, and Priorities, C.o.S.C. Injury, The National Academies Press, Washington, D.C 2005, p 1.

[3] M. E. L. Van den Berg, J. M. Castellote, I. Mahillo-Fernandez, J. de Pedro-Cuesta, Neuroepidemiology 2010, 34, 184.

[4] R. Talac, J. A. Friedman, M. J. Moore, L. Lu, E. Jabbari, A. J. Windebank, B. L. Currier, M. J. Yaszemski, Biomaterials 2004, 25, 1505.

[5] K. S. Straley, C. W. P. Foo, S. C. Heilshorn, J. Neurotrauma 2010, $27,1$.

[6] W. Coleman, D. Benzel, D. Cahill, T. Ducker, F. Geisler, B. Green, M. Gropper, J. Goffin, P. I. Madsen, D. Maiman, S. Ondra, M. Rosner, R. Sasso, G. Trost, S. Zeidman, J. Spinal Disord. 2002, 13, 185.

[7] M. B. Bracken, M. J. Shepard, W. F. Collins, T. R. Holford, D. S. Baskin, H. M. Eisenberg, E. Flamm, L. Leo-Summers, J. C. Maroon, L. F. Marshall, P. L. Perot, J. Piepmeier, V. K. H. Sonntag, F. C. Wagner, J. L. Wilberger, H. R. Winn, W. Young, J. Neurosurg. 1992, 76, 23.

[8] M. B. Bracken, M. J. Shepard, T. R. Holford, L. Leo-Summers, E. F. Aldrich, M. Fazl, M. Fehlings, D. L. Herr, P. W. Hitchon, L. F. Marshall, R. P. Nockels, V. Pascale, P. L. Perot, J. Piepmeier, V. K. H. Sonntag, F. Wagner, J. E. Wilberger, H. R. Winn, W. Young, JAMA, J. Am. Med. Assoc. 1997, 277, 1597.
[9] M. B. Bracken, M. J. Shepard, T. R. Holford, L. Leo-Summers, E. F. Aldrich, M. Fazl, M. G. Fehlings, D. L. Herr, P. W. Hitchon, L. F. Marshall, R. P. Nockels, V. Pascale, P. L. Perot, J. Piepmeier, V. K. H. Sonntag, F. Wagner, J. E. Wilberger, H. R. Winn, W. Young, J. Neurosurg. 1998, 89, 699.

[10] F. Geisler, W. Coleman, G. Grieco, F. Dorsey, D. Poonian, Spine 2001, 26, S87.

[11] I. Grijalva, G. Guízar-Sahagún, G. Castañeda-Hernández, D. Mino, H. Maldonado-Julián, G. Vidal-Cantú, A. Ibarra, O. Serra, H. Salgado-Ceballos, R. Arenas-Hernández, Pharmacotherapy 2003, 23, 823 .

[12] P. Nance, J. Bugaresti, K. Shellenberger, W. Sheremata, A. Martinez-Arizala, Neurology 1994, 44, S44.

[13] G. Onose, A. Anghelescu, D. F. Muresanu, L. Padure, M. A. Haras, C. O. Chendreanu, L. V. Onose, A. Mirea, A. V. Ciurea, W. S. El Masri, K. R. H. von Wild, Spinal Cord. 2009, 47, 716.

[14] S. R. Cerqueira, J. M. Oliveira, N. A. Silva, H. Leite-Almeida, S. Ribeiro-Samy, A. Almeida, J. F. Mano, N. Sousa, A. J. Salgado, R. L. Reis, Small 2012, 9, 738.

[15] D. C. Baptiste, M. G. Fehlings, J. Neurotrauma 2006, 23, 318.

[16] P. Lu, M. H. Tuszynski, Exp. Neurol. 2008, 209, 313.

[17] S. Rossignol, M. Schwab, M. Schwartz, M. G. Fehlings, J. Neurosci. 2007, 27, 11782.

[18] S. Thuret, L. D. F. Moon, F. H. Gage, Nat. Rev. Neurosci. 2006, 7, 628.

[19] A. J. Salgado, O. P. Coutinho, R. L. Reis, Macromol. Biosci. 2004, $4,743$.

[20] N. A. Silva, A. J. Salgado, R. A. Sousa, J. T. Oliveira, A. J. Pedro, H. Leite-Almeida, R. Cerqueira, A. Almeida, F. Mastronardi, J. F. Mano, N. M. Neves, N. Sousa, R. L. Reis, Tissue Eng., Part A 2010, 16, 45.

[21] N. A. Silva, M. J. Cooke, R. Y. Tam, N. Sousa, A. J. Salgado, R. L. Reis, M. S. Shoichet, Biomaterials 2012, 33, 6345.

[22] A. L. Oliveira, E. C. Sousa, N. A. Silva, N. Sousa, A. J. Salgado, R. L. Reis, J. Mater. Sci.: Mater. Med. 2012, 23, 2821.

[23] N. N. Madigan, S. McMahon, T. O'Brien, M. J. Yaszemski, A. J. Windebank, Respir. Physiol. Neurobiol. 2009, 169, 183.

[24] K. Kataoka, Y. Suzuki, M. Kitada, K. Ohnishi, K. Suzuki, M. Tanihara, C. Ide, K. Endo, Y. Nishimura, J. Biomed. Mater. Res. 2001, 54, 373.

[25] P. J. Johnson, S. R. Parker, S. E. Sakiyama-Elbert, J. Biomed. Mater. Res. A 2012, 92A, 152.

[26] K. Moore, M. Macsween, M. Shoichet, Tissue Eng. 2006, 12, 267.

[27] J. C. de la Torre, Brain Res. Bull. 1982, 9, 545.

[28] R. Marchand, S. Woerly, L. Bertrand, N. Valdes, Brain Res. Bull. 1993, 30, 415.

[29] P. Lesný, M. Přádný, P. Jendelová, J. Michálek, J. Vacík, E. Syková, J. Mater. Sci. Mater. Med. 2006, 17, 829.

[30] M. Oudega, S. E. Gautier, P. Chapon, M. Fragoso, M. L. Bates, J.-M. Parel, M. Bartlett Bunge, Biomaterials 2001, 22, 1125.

[31] C. M. Patist, M. B. Mulder, S. E. Gautier, V. Maquet, R. Jérôme, M. Oudega, Biomaterials 2004, 25, 1569.

[32] S. Yoshii, M. Oka, M. Shima, A. Taniguchi, Y. Taki, M. Akagi, J. Biomed. Mater. Res., A 2004, 70A, 569.

[33] S. Rochkind, A. Shahar, M. Amon, Z. Nevo, Neurol Res. 2002, 24, 355.

[34] Y. D. Teng, E. B. Lavik, X. Qu, K. I. Park, J. Ourednik, D. Zurakowski, R. Langer, E. Y. Snyder, Proc. Natl. Acad. Sci. U. S. A. 2002, 99, 3024

[35] H. Nomura, C. Tator, M. Shoichet, J. Neurotrauma 2006, 23 , 496.

[36] R. Rocha, Ld. Silva, J. Pradella, World J. Microbiol. Biotechnol. 2008, 24, 427 .
Macromol. Biosci. 2013, DOI: 10.1002/mabi.201300178

(c) 2013 WILEY-VCH Verlag GmbH \& Co. KGaA, Weinheim

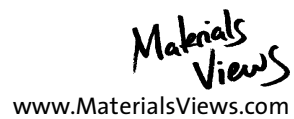

www.MaterialsViews.com

Early View Publication; these are NOT the final page numbers, use DOI for citation !! 
[37] G.-O. Chen, O. Wu, Biomaterials 2005, 26, 6565.

[38] G. T. Köse, S. Ber, F. Korkusuz, V. Hasirci, J. Mater. Sci. Mater. Med. 2003, 14, 121.

[39] N. Sultana, M. Wang, J. Mater. Sci. Mater. Med. 2008, 19, 25552561.

[40] L. S. Nair, C. T. Laurencin, Prog. Polym. Sci. 2007, 32, 762.

[41] D. Yucel, G. T. Kose, V. Hasirci, Biomaterials 2010, 31, 1596.

[42] W. Chen, Y. W. Tong, Acta Biomater. 2012, 8, 540.

[43] A. J. Salgado, O. P. Coutinho, R. L. Reis, Tissue Eng. 2004, 10, 465.

[44] J. M. Capasso, B. R. Cossío, T. Berl, C. J. Rivard, C. Jiménez, Biomol Eng. 2003, 20, 133.

[45] M. V. Berridge, P. M. Herst, A. S. Tan, Biotechnol. Annu. Rev. 2005, 11, 127.

[46] A. J. Salgado, J. S. Fraga, A. R. Mesquita, N. M. Neves, R. L. Reis, N. Sousa, Stem Cells Dev. 2010, 19, 1067.

[47] R. Sarugaser, J. Ennis, W. L. Stanford, J. E. Davies, "Isolation, Propagation, and Characterization of Human Umbilical Cord Perivascular Cells (HUCPVCs)", in Stem Cells in Regenerative Medicine: Methods and Protocols, J. Audet, W. L. Stanford, Eds., Humana Press, Toronto 2009, p 269.

[48] J. M. Gimble, F. Guilak, Cytotherapy 2003, 5, 362.

[49] N. A. Silva, R. A. Sousa, A. O. Pires, N. Sousa, A. J. Salgado, R. L. Reis, J. Biomed. Mater. Res., Part A 2012, 100A, 470.

[50] N. A. Silva, R. A. Sousa, J. S. Fraga, M. Fontes, H. Leite-Almeida, R. Cerqueira, A. Almeida, N. Sousa, R. L. Reis, A. J. Salgado, Tissue Eng. Part C, Methods 2013, 19, 101.

[51] J. edý, L. Urdzíková, P. Jendelová, E. Syková, Neurosci. Biobehav. Rev. 2008, 32, 550.

[52] N. Zhang, H. Yan, X. Wen, Brain Res. Rev. 2005, 49, 48.

[53] T. Takezawa, Biomaterials 2003, 24, 2267.

[54] N. Davidenko, T. Gibb, C. Schuster, S. M. Best, J. J. Campbell, C. J. Watson, R. E. Cameron, Acta Biomater. 2012, 8, 667.

[55] T. W. Carone, PhD thesis, Syracuse University 2008.

[56] E. C. Clarke, "Spinal Cord Mechanical Properties", in Neural Tissue Biomechanics, L. E. Bilston, Ed., Springer, Berlin 2011, p 25.

[57] J. M. Anderson, R. W. Bianco, J. F. Grehan, B. C. Grubbs, S. R. Hanson, K. D. Hauch, M. Lahti, J. P. Mrachek, S. J. Northup, B. D. Ratner, F. J. Schoen, E. L. Schroeder, C. W. Schumacher, C. A. Svendsen, "Biological Testing of Biomaterials", in Biomaterials Science: An introduction to Materials in Medicine, B. D. Ratner, A. S. Hoffman, F. J. Schoen, J. E. Lemons, Eds., Elsevier Academic Press, London 2004, p 355.
[58] I. R. Freshney, "Subculture and Cell Lines", in Culture of Animal Cells: A Manual of Basic Technique, $5^{\text {th }}$ edition, WileyLiss, New Jersey 2005, p 199.

[59] I. R. Freshney, "Biology of Cultured Cells", in Culture of Animal Cells: A Manual of Basic Technique, $5^{\text {th }}$ edition, WileyLiss, New Jersey 2005, p 31.

[60] R. S. Tewarie, A. Hurtado, R. H. Bartels, A. Grotenhuis, M. Oudega, J. Spinal Cord. Med. 2009, 32, 105.

[61] J. Lu, Y. Wu, N. Sousa, O. F. X. Almeida, Development 2005, 132, 3231.

[62] L. da Silva Meirelles, A. M. Fontes, D. T. Covas, A. I. Caplan, Cytokine Growth Factor Rev. 2009, 20, 419.

[63] G. Brooke, M. Cook, C. Blair, R. Han, C. Heazlewood, B. Jones, M. Kambouris, K. Kollar, S. McTaggart, R. Pelekanos, A. Rice, T. Rossetti, K. Atkinson, Semin. Cell Dev. Biol. 2007, 18, 846.

[64] C. A. Ribeiro, A. J. Salgado, J. S. Fraga, N. A. Silva, R. L. Reis, N. Sousa, J. Tissue Eng. Regen. Med. 2011, DOI: 10.1002/term.365

[65] N. Li, H. Sarojini, J. An, E. Wang, J. Neurochem. 2010, 112, 1527.

[66] N. A. Silva, J. M. Gimble, N. Sousa, R. L. Reis, A. J. Salgado, Stem Cells and Development 2013, DOI: 10.1089/scd.2012.0524

[67] D. Baksh, R. Yao, R. S. Tuan, Stem Cells 2007, 25, 1384.

[68] S. Kern, H. Eichler, J. Stoeve, H. Klüter, K. Bieback, Stem Cells 2006, 24, 1294.

[69] S. C. Barnett, J. Neurotrauma 2004, 21, 375.

[70] M. Sasaki, J. A. Black, K. L. Lankford, H. A. Tokuno, S. G. Waxman, J. D. Kocsis, J. Neurosci. 2006, 26, 1803.

[71] M. Sasaki, K. L. Lankford, M. Zemedkun, J. D. Kocsis, J. Neurosci. 2004, 24, 8485.

[72] A. Ramón-Cueto, G. W. Plant, J. Avila, M. B. Bunge, J. Neurosci. 1998, 18, 3803.

[73] A. Ramón-Cueto, M. I. Cordero, F. F. Santos-Benito, J. Avila, Neuron 2000, 25, 425.

[74] Y. Li, P. M. Field, G. Raisman, Science 1997, 277, 2000.

[75] H. H. Nash, R. C. Borke, J. J. Anders, J. Neurosci. 2002, 22, 7111.

[76] N. Keyvan-Fouladi, G. Raisman, Y. Li, J. Neurosci. 2003, 23 , 9428.

[77] E. Fournier, C. Passirani, C. N. Montero-Menei, J. P. Benoit, Biomaterials 2003, 24, 3311.

[78] L. Tang, J. Eaton, Am. J. Clin. Pathol. 1995, 103, 466.

[79] A. G. Mikos, L. V. McIntire, J. M. Anderson, J. E. Babensee, Adv. Drug Delivery Rev. 1998, 33, 111.

[80] J. E. Babensee, M. V. Sefton, Tissue Eng. 2000, 6, 165.

[81] N. Sultana, T. H. Khan, J. Nanomater. 2012, 2012, 12.

[82] M. Zinn, B. Witholt, T. Egli, Adv. Drug Delivery Rev. 2001, 53, 5.

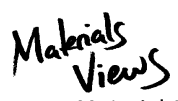

www.MaterialsViews.com
Macromol. Biosci. 2013, DOI: 10.1002/mabi.201300178

(C) 2013 WILEY-VCH Verlag GmbH \& Co. KGaA, Weinheim 